FINAL TECHNICAL REPORT

\title{
Novel Carbon Films for Next Generation Rotating Equipment Applications
}

February 20, 2006

\section{DE-FC36-02ID14257}

Project Period: 03/30/3002-06/30/2005

Michael McNallan

312-996-2436

University of Illinois at Chicago

842 W. Taylor St.

Chicago, IL 60607

mcnallan@uic.edu

\section{Subcontractors:}

\author{
Ali Erdemir \\ 630-252-6571 \\ Argonne National Laboratory \\ Argonne, IL 60439 \\ erdemir@anl.gov \\ Yury Gogotsi \\ 215-895-6446 \\ Drexel University \\ Philadelphia, PA 19104 \\ gogotsi@drexel.edu
}


Acknowledgment: "This report is based upon work supported by the U. S. Department of Energy under Award No DE-FC07-02ID14257 “.

Disclaimer: "Any findings, opinions, and conclusions or recommendations expressed in this report are those of the author(s) and do not necessarily reflect the views of the Department of Energy"

Proprietary Data Notice: If there is any patentable material or protected data in the report, the recipient, consistent with the data protection provisions of the award, must mark the appropriate block in Section $\mathrm{K}$ of the DOE F 241.3, clearly specify it here, and identify them on appropriate pages of the report. Other than patentable material or protected data, reports must not contain any proprietary data (limited rights data), classified information, information subject to export control classification, or other information not subject to release. Protected data is specific technical data, first produced in the performance of the award, which is protected from public release for a period of time by the terms of the award agreement. Reports delivered without such notice may be deemed to have been furnished with unlimited rights, and the Government assumes no liability for the disclosure, reproduction or use of such reports. 


\section{Table of Contents}

Page

1. Introduction 9

2. Background 10

3. Results and Discussion

A. CDC Growth Rates 12

i. Parabolic Kinetics 14

ii. Implications of Parabolic Kinetics 15

B. CDC Mechanical Properties 18

C. Effects of Post-Synthesis Processing in Hydrogen on Mechanical Properties 21

D. Tribological performance of CDC 21

E. Effects of Surface Polishing on Tribological Performance of CDC 23

F. Effects of Post-Synthesis Processing in Hydrogen on Friction 25

G. Wear of CDC in Pin-on-Disk Tests 29

$\mathrm{H}$. Tribological performance of CDC/NFC couples 32

I. Performance of CDC treated pump seals 35

4. Accomplishments 40

5. Technical Presentations at National or International

6. Publications 43

7. Conclusions 44

8. Recommendations 45

References 46 


\section{List of Figures}

Figure 1. Schematic diagram of horizontal tube furnace and gas flow control system for CDC synthesis on SiC pump seal rings 12

Figure 2. Optical micrograph of CDC layer produced on sintered alpha SiC after one hour treatment in flowing $\mathrm{Ar}-3.5 \% \mathrm{Cl}_{2}$ at $1000^{\circ} \mathrm{C}$. Note the rough interface between the CDC and the $\mathrm{SiC}$, which helps to anchor the layer to the substrate and prevent spallation.... 13

Figure 3. Backscattered Scanning electron micrograph of CDC layer produced on sintered alpha $\mathrm{SiC}$ after one hour treatment in flowing $\mathrm{Ar}-3.5 \% \mathrm{Cl}_{2}$ at $1000^{\circ} \mathrm{C}$.

Figure 4. CDC layer thickness versus time for growth on alpha $\mathrm{SiC}$ in $\mathrm{Ar}-3.5 \% \mathrm{Cl}_{2}$ at $1000^{\circ} \mathrm{C}$ 14

Figure 5. CDC layer thickness versus time for growth on alpha $\mathrm{SiC}$ in $\mathrm{Ar}-3.5 \% \mathrm{Cl}_{2}$ at $900^{\circ} \mathrm{C}$ 15

Figure 6. Cross section scanning electron micrograph of CDC layer grown on $\mathrm{SiC}$ in $\mathrm{Ar}$ $3.5 \% \mathrm{Cl}_{2}$ for two hours at $900^{\circ} \mathrm{C}$. X-ray fluorescence analysis was performed for chlorine at

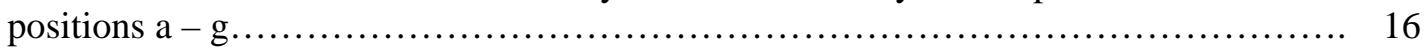

Figure 7. Chlorine concentration in CDC as a function of position within the CDC layer formed on $\mathrm{SiC}$ in $\mathrm{Ar}-3.5 \% \mathrm{Cl}_{2}$ for two hours at $900^{\circ} \mathrm{C}$

Figure 8. Load-displacement curve for nano-indentation 18

Figure 9. Hardness of CDC produced on $\mathrm{SiC}$ by treatment in $\mathrm{Cl}_{2} / \mathrm{HCl}$ gas mixtures at $1000^{\circ} \mathrm{C}$ as a function of $\mathrm{Cl}_{2} / \mathrm{HCl}$ ratio

Figure 10. Scanning electron micrographs of CDC surfaces produced in (a) $\mathrm{Ar}-3.5 \% \mathrm{Cl}_{2}$ two hour treatment at $1000^{\circ} \mathrm{C}$. (b) $\mathrm{Cl}_{2} / \mathrm{H}_{2}$ ratio of $1 / 0.37$ two hour treatment at $1000^{\circ} \mathrm{C}$. (c) $\mathrm{Cl}_{2} / \mathrm{HCl}$ ratio of $1 / 0.5$ one hour treatment at $1000^{\circ} \mathrm{C}$.

Figure 11 Friction coefficient versus sliding distance in pin-on-disk test on CDC produced on $\mathrm{SiC}$ by one-hour treatment in $\mathrm{Ar}-3.5 \% \mathrm{Cl}_{2}$ at $1000^{\circ} \mathrm{C}$. Normal load, $5 \mathrm{~N}$, rotation rate, $500 \mathrm{rpm}$. 22

Figure 12. Friction coefficients versus sliding distance in pin-on-disk tests on CDC produced on $\mathrm{SiC}$ by eight and sixteen hour treatments in $\mathrm{Ar}-3.5 \% \mathrm{Cl}_{2}$ at $900^{\circ} \mathrm{C}$. Normal load, $5 \mathrm{~N}$, rotation rate, $200 \mathrm{rpm}$. 23

Figure 13. Friction coefficient versus time for CDC grown in $\mathrm{Ar}-12 \% \mathrm{Cl}_{2}-4.5 \% \mathrm{H}_{2}$ for three hours at $1100^{\circ} \mathrm{C}$. The effect of surface polishing is illustrated. The polished surface has approximately $40 \%$ lower friction coefficient after the initial transient dies out............. 24

Figure 14. Friction coefficients versus sliding distance in pin-on-disk tests on CDC produced on $\mathrm{SiC}$ by six hour treatments in $\mathrm{Cl}_{2} / \mathrm{H}_{2}$ mixture in ratio of $1 / 0.25$ at $900^{\circ} \mathrm{C}$. Normal load, $5 \mathrm{~N}$, rotation rate, $200 \mathrm{rpm}$.... .25 
Figure 15. Friction coefficients versus sliding distance in pin-on-disk tests on CDC produced on $\mathrm{SiC}$ by one, two, and four hour treatments in $\mathrm{Cl}_{2} / \mathrm{HCl}$ mixture in ratio of $1 / 0.5$ at

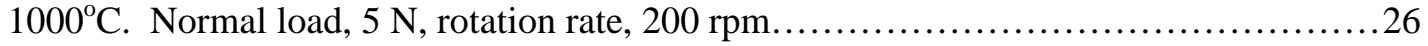

Figure 16. Friction coefficients versus sliding distance in pin-on-disk tests on CDC produced on SiC by 6 hour treatment in $\mathrm{Cl}_{2} / \mathrm{H}_{2}$ mixture in ratio of $1 / 0.25$ at $900^{\circ} \mathrm{C}$ and after postsynthesis treatment of the same CDC in $\mathrm{Ar}-5 \% \mathrm{H}_{2}$ for 8 hours at $800^{\circ} \mathrm{C}$. Normal load, $5 \mathrm{~N}$, rotation rate, $200 \mathrm{rpm}$ 27

Figure 17. Friction coefficient versus testing time during pin-on-disk testing of CDC with and without hydrogen post treatment, tested in laboratory air and in dry nitrogen. The friction coefficient in dry nitrogen decreases to approximately 0.05 when hydrogen treated CDC

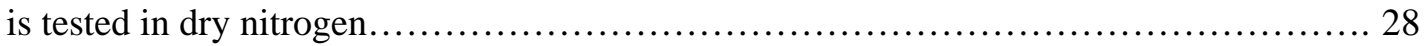

Figure 18. Friction coefficient versus test time for hydrogen treated CDC. Test extended for 5 hours duration, with friction coefficient falling below $0.04 \ldots \ldots \ldots 28$

Figure 19. Friction coefficient versus sliding distance in pin-on-disk test on CDC produced on $\mathrm{SiC}$ by 31 hour treatment in $\mathrm{Ar}-3.5 \% \mathrm{Cl}_{2}$ at $1000^{\circ} \mathrm{C}$. Normal load, $5 \mathrm{~N}$, sliding

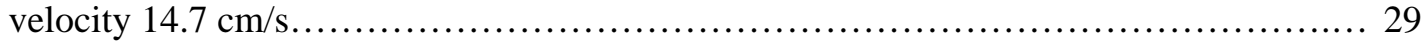

Figure 20. Wear track profile for CDC treated SiC specimen after $260 \mathrm{~m}$ sliding in pinon-disk test. 30

Figure 21. Wear track profile for CDC treated SiC specimen after $1360 \mathrm{~m}$ sliding in pinon-disk test. 30

Figure 22. Wear volume versus sliding distance for CDC in pin-on-disk test with 3/8” silicon nitride ball as load of $5 \mathrm{~N}$ and sliding velocity of $14.7 \mathrm{~cm} / \mathrm{s} \ldots \ldots \ldots \ldots \ldots \ldots \ldots \ldots \ldots \ldots \ldots$

Figure 23. Friction coefficient versus sliding time for steel ball sliding against a polished CDC layer in laboratory air and in dry nitrogen. Polishing of the CDC surface lowers the friction coefficient to the range of 0.1 , and testing in dry nitrogen reduces it further to the range of 0.04 32

Figure 24. Friction coefficient versus sliding time for NFC coated steel ball sliding against a polished CDC layer in laboratory air and in dry nitrogen. With a NFC coating on the steel ball, s the friction coefficient in laboratory air drops to the range of 0.07 , and testing in dry nitrogen reduces it further to the range of 0.02 , nearly a $50 \%$ reduction from the value without NFC.

Figure 25. Three dimensional profilometry trace of NFC coated steel ball after testing against CDC, and before any cleaning. Note that there is no indication of a transfer layer or any significant sign of wear of material from the surface.

Figure 26. photograph of Dynamic Seal Test Facility at Argonne National Laboratory

Figure 27. Detail of Seal Ring assembly in dynamic seal tester. 36 
Figure 28. Non-contact profilometry scan of CDC treated SiC seal after one day testing in Dynamic Seal Test facility at 20 psi......................................... 37

Figure 29. Non-contact profilometry scan of CDC treated SiC seal after one day testing in Dynamic Seal Test facility at 20 psi and one day testing at 40 psi.................... 37

Figure 30. Non-contact profilometry scan of CDC treated SiC seal after one day testing in Dynamic Seal Test facility at $20 \mathrm{psi}$, one day testing at $40 \mathrm{psi}$ and one day testing

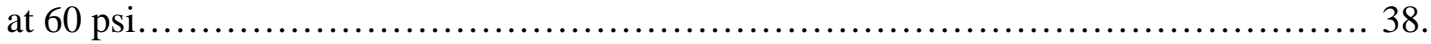

Figure 31. Non-contact profilometry scan of CDC treated SiC seal after one day testing in Dynamic Seal Test facility at 20 psi, one day testing at 40 psi, one day testing at 60 psi and

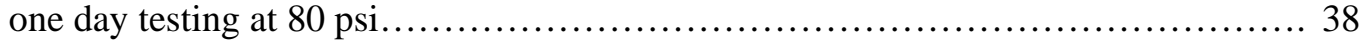

Figure 32. Non-contact profilometry scan of CDC treated SiC seal after one day testing in Dynamic Seal Test facility at $20 \mathrm{psi}$, one day testing at $40 \mathrm{psi}$, one day testing at $60 \mathrm{psi}$,

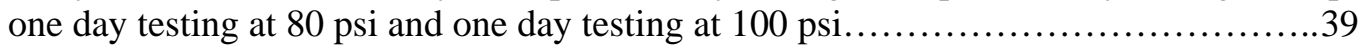

Figure 33. Non-contact profilometry scan of CDC treated SiC seal after one day testing in Dynamic Seal Test facility at 20 psi, one day testing at 40 psi, one day testing at $60 \mathrm{psi}$, one

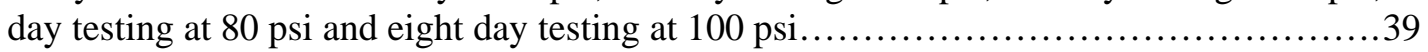




\section{Executive Summary}

This report describes the results of a research program addressing low friction wear resistant coatings for bearing and seals in high speed rotating equipment. Frictional energy losses on such equipment are responsible for significant energy inefficiencies in pumps and similar equipment, and wear of these seals leads to product losses and environmental pollution. Improvements in the performance of these devices as a result of the application of coatings can result in substantial energy savings.

The coatings investigated in this program are Near Frictionless Carbon (NFC), a high hydrogen content diamondlike carbon deposited by plasma enhanced chemical vapor deposition, and Carbide Derived Carbon (CDC), a nanostructured carbon produced by extracting the metal component from a ceramic carbide by exposing it to a halogen gas at moderately elevated temperature $\left(600-1200^{\circ} \mathrm{C}\right)$. CDC is of particular interest because it can be produced at low cost on carbide materials such as $\mathrm{SiC}$ and WC, which are already widely used in the seal industry. Carbon coatings were produced in the laboratory and then subjected to characterization by Raman spectroscopy, X-ray diffraction, optical microscopy, scanning and transmission electron microscopy, and a series of mechanical and tribological tests.

The growth kinetics of CDC layers on $\mathrm{SiC}$ have been characterized by measuring the thickness of CDC produced by exposure to flowing $\mathrm{Ar}-3.5 \% \mathrm{Cl}_{2}$ at temperatures between 900 and $1000^{\circ} \mathrm{C}$. The growth kinetics follow a parabolic rate law with transport of chlorine through the growing CDC layer apparently controlling the rate. It was verified that treatments on the order of 1 hour at $1000^{\circ} \mathrm{C}$ are sufficient to produce tribologically beneficial layers of CDC on the order of $10 \mu \mathrm{m}$ thick.

The physical and mechanical properties of CDC can be manipulated by growing the CDC in a reactive gas mixture of chlorine and hydrogen, rather than chlorine alone. The hardness and elastic modulus of the CDC were measured by nano-indentationto minimize interferences between the samples. In general, the hardness of the CDC increases when more hydrogen was present during chlorination, whether as $\mathrm{H}_{2}$ or as $\mathrm{HCl}$. The surface roughness of the CDC is lower when the chlorination gas mixture contains $\mathrm{HCl}$ rather than $\mathrm{H}_{2}$.

The tribological properties of CDC coated surfaces were examined in pin-on-disk tests performed in dry nitrogen and open air sliding against a silicon nitride ball. Polishing of the CDC coating reduces the surface roughness and reduces the initial friction coefficient as well. Polishing of the CDC appears to improve its overall performance in many respects. Specimens treated in $\mathrm{CL}_{2} / \mathrm{HCl}$ gas mixtures generally had more consistent properties than similar specimens treated in $\mathrm{CL}_{2} / \mathrm{H}_{2}$. Post synthesis treatment in hydrogen gas reduces the friction coefficient of the layer in service without substantially changing its hardness. Hydrogen treatment also removes residual chlorine from the CDC. Unlike the situation with most graphitic carbons, where adsorbed water molecules between the graphitic carbon planes contributes to the lubrication effect, the 
friction coefficient is lower in dry nitrogen than in humid air. This suggests that CDC may be an effective lubricant in vacuum or dry inert gas environments.

The wear rate of CDC in dry sliding against silicon nitride ceramic balls was measured corresponds to a value on the order of $1 \times 10-6 \mathrm{~mm} 3 / \mathrm{Nm}$. This is approximately two orders of magnitude lower than is observed with conventional oil lubrication under similar conditions. The wear rate is higher during the first 20-30 minutes of the test, but subsequently is stable. Low wear rates were more likely to be associated with low friction coefficients on the CDC than with high hardness.

The friction coefficient between CDC and a test surface were further investigated by comparing the results obtained with a steel ball in the pin-on-disk equipment with the results after the ball was coated with NFC. The friction coefficient in dry nitrogen was reduced by nearly 50\%, when the counter-surface was coated with NFC before the experiments. This demonstrates that these two coating can provide synergistic benefits.

The performance of the CDC coated rings was further tested in the dynamic seal tester at Argonne National Laboratory. In the tester, rings are installed in a pump and tested over a range of parameters, with the pressure and pump speed increasing stepwise throughot the test. CDC treated rings performed well with minimal interruptions at pressures up to $100 \mathrm{psi}$ and high flow rates.

The results of the tests perform suggest that CDC layers can be applied inexpensively and can produce substantial improvements in the performance and reliability of pump seals. Carbide Derivative Technology, Inc. (CDTI), and Illinois based company set up to exploit the benefits of CDC, has licensed the technology from the University of Illinois, and is proceeding with plans to market this coating to the pump and chemical industries. The principal investigators on this program are collaborating with CDTI personnel and seeking funding for research addressing high rate production and accurate control of CDC layer thickness and properties. 


\section{Introduction}

This report describes the results of a research program supported by the Office of Industrial Technology of the U.S. Department of Energy. Because a substantial fraction of the energy used in the U.S. economy is imported from foreign sources, the economy is very sensitive to increases $\mathrm{n}$ energy costs. Improving energy efficiency of industrial operations reduces the need for imported energy without decreasing the ecomomic output, to the benefit and well-being of Americans. This research project was supported through the Industrial Materials for the Future program, which supports the development of new materials that can provide these benefits.

Pump seals are ubiquitous devices in industrial systems where fluids must be transferred from one vessel to another. IN a pump seal, the transferred fluids are separated from the outside environment by surfaces which are in sliding contact due to the rapid rotating motion of the pumping components. Failure, or poor performance of pump seals results in leakage of the fluid into the environment, causing economic loss, pollution of the environment, and in some cases, fire or other damaging industrial accidents.

Because the seal faces are in sliding contact, the tribological properties, friction and wear rates, of the surfaces are critical to their performance. The friction coefficients control the amount of energy loss from the pumps into the seals so that lower friction coefficients directly improve the energy efficiency of pumping systems. High friction coefficients can also contribute to heat build up at the seal faces, which can cause fire or thermal degradation of polymeric components of the pumping system.

Pump seal faces are typically produced from hard, wear resistant materials, such as SiC or WC. Some seal faces are also produced form low friction graphite based materials, but wear of these materials often limits the operating lifespan of the equipment. Seal faces produced from composites of SiC and graphite have been used to obtain a combination of low friction coefficient and wear resistance, but the volume fraction of graphite that can be used without loss in hardness is limited, so that optimal properties cannot be obtained by this approach.

The low friction component is more effective if it is introduced as a coating at the contacting surfaces of the materials. Carbon, whether as graphite, diamond, or oen of its non-equilibrium forms, can be applied as a low friction coefficient coating to tribological materials. Crystalline diamond has the disadvantage that it tends to grow as faceted grains, which cause severe wear on the counterface unless the surface is polished before used. Diamond film deposition processes are also generally slow, energy intensive processes that are expensive to apply. Adhesion between diamond films and the substrate material has also bee a problem, with spallation and delamination of the coating being common failure mechanisms for diamond coated seal faces. This project addressed the application of two new types of carbon coatings in the important tribological application of sealing surfaces in rotating equipment.

Carbide derived carbon (CDC) is a form of carbon produced by reaction of metal carbides with halogens at moderately elevated temperatures $\left(600-1200^{\circ} \mathrm{C}\right)$. The halogen (usually chorine) reacts with the metal component of the carbide and 
removes it as a volatile specie, leaving the carbon behind. At the treatment temperatures used, the carbon $\left(\mathrm{sp}^{3}\right.$ bonded in the original carbide), is not able to relax into the thermodynamically stable $\mathrm{sp}^{2}$ bonded graphite phase, and instead, remains in a metastable state containing amorphous carbon with both $\mathrm{sp}^{2}$ and $\mathrm{sp}^{3}$ bonding as well as nanocrystalline diamond and nested fullerene structures (carbon "onions"). CDC can be conveniently grown on hard carbide ceramics such as SiC which is widely used in bearings and seal rings without a requirement for high cost plasma or vacuum systems. CDC conversion coatings on SiC reduce the friction coefficient in sliding wear and have better resistance to wear than graphite because of their higher hardness and better resistance to spallation than diamond coatings because of their graded mechanical properties, which match those of the carbide substrate across the interface. In this project CDC coatings have been grown on SiC pump seal rings, and improved friction and wear performance has been demonstrated.

Near frictionless carbon (NFC) is a form of diamond like carbon (amorphous $\mathrm{sp}^{3}$ bonded carbon), with a high hydrogen content due to deposition under high hydrogen conditions. Unlike CDC, NFC can be deposited onto any surface, and the high hydrogen content of the material leads to low friction properties under sliding wear conditions. NFC coatings have been applied in sliding couples along with CDC treated $\mathrm{SiC}$ to produce lower friction coefficients than would be produced by CDC coatings alone. In addition, the principle of hydrogenation to reduce friction, which has been demonstrated in NFC, has been expanded into CDC by using hydrogen post-treatments of CDC coated SiC surfaces to modify the CDC properties and reduce sliding friction further.

The project was implemented by a three institution team consisting of

1. Professor Michael McNallan at the University of Illinois at Chicago (UIC), with graduate students Allen Lee, Christopher White, Ranyi Zhu and Marcin Tlustochowicz. The UIC team focused on synthesis of CDC on laboratory SiC coupons and commercial SiC components, characterization of the CDC products using Raman and electron spectroscopy and mechanical testing, and on tribological testing on laboratory and commercial parts.

2. Dr. Ali Erdemir at the Argonne National Laboratory (ANL), with post-doctoral research associate Dr. Andriy Kovalchenko (supported through the UIC budget during some parts of the program). The ANL team focused on synthesis of NFC coatings and tribological testing and characterization of coated parts. For some parts of the program, UIC students holding courtesy appointments at ANL used ANL equipment to perform tests.

3. Professor Yury Gogotsi at Drexel University (DU), with graduate student Elizabeth Carroll. The DU team focused on synthesis of CDC in high chlorine content gas mixtures and on microstructural and physical characterization of CDC coatings.

\section{Background}

Mechanical shaft seals are used in pumps that are critical to the operation of the paper, pulp, and chemical process industry, as well as the petroleum and nuclear power generating plants to prevent the leakage of gases and hazardous chemicals from rotating equipment. Face seals have extremely flat and smooth surfaces 
(flatness: 1-2 Helium light bands), low friction coefficient, high hardness, high corrosion resistance, high thermal conductivity, and high thermal shock resistance. Presently, SiC, WC and graphite are widely used by seals industry as the primary seal materials (1-3), however, the mechanical, tribological and chemical properties of these materials individually place upper limits on the operational conditions and hence limit the overall life-span of the seal. With the development of new applications and technologies that require pumping systems to operate at higher pressures and flow rates, there are increasing demands on operational limits and total life span of rotating shaft seals (3). This need triggered the search for materials with superior mechanical, tribological and chemical properties.

Diamond, because of its outstanding hardness and resistance to chemical attack is a promising candidate for such applications. Moreover, with the advances in CVDdiamond technology it is possible to deposit a diamond in thin films, over a large area, on a variety of substrate materials (4). However, diamond coatings produced by conventional chemical vapor deposition (CVD) techniques exhibit sharp, faceted crystal morphology with high surface roughness $(\mathrm{Ra}=0.1 \mu \mathrm{m}-1 \mu \mathrm{m})$, which causes high friction and a high amount of wear on the seal counterface leading to seal failure at an early stage. Some of the workers have reported enhancement in the wear life of CVD diamond coated seals when tested for short duration (3), however surface morphology of these coatings is found to play an extremely important role in deciding wear life of the seal (5). In order to avoid high wear on the counterface, the conventional diamondcoated faces need to be extensively polished before use, which results in excessive added fabrication cost

Diamond and diamondlike carbon films have some disadvantages in practice, however. They generally require the use of high vacuum systems and energy intensive plasma processes, which can be expensive.(6) In service, thin diamond or diamond like carbon coatings can fail by delamination or fatigue cracking at the interface between the coating and the substrate.(6,7) Adhesion of the carbon film to the substrate has been a continuing problem, and pretreatments are usually necessary to improve the adhesion. (8-10)

The aim of this program was to combine two complementary carbon technologies to achieve the longest wear life, the highest reliability and the greatest energy savings in mechanical pumps and other rotating machinery applications. One of the processes to be exploited in this project involves the synthesis of a superlow friction carbon film on SiC seals, while the other involves a chemical conversion that etches out Si from SiC to leave a surface film of carbon with structure and properties ranging from graphite to diamond. These converted films have excellent resistance to spallation and delamination, two common failure mechanisms for carbon coatings. The combination of these two technologies has the potential to produce optimal coatings which reduce energy consumption, improve product reliability, and reduce toxic emissions into the environment. 


\section{Results and Discussion}

\section{A. CDC layer Growth Kinetics}

A key requirement for commercial application of CDC coatings on carbide surfaces is accurate knowledge of the kinetics of the conversion reaction. In spite of considerable research, some inconsistencies had remained regarding the thickness of the CDC layer produced by chlorine treatment as a function of time and temperature. Part of this ambiguity may result from different polytypes of SiC, which can be obtained in the form of single crystal or polycrystalline materials, densified by different methods by the $\mathrm{SiC}$ material suppliers. In order to clarify these kinetics, a series of experiments were performed in which CDC was synthesized on the surfaces of commercial sintered SiC pump seal faces commonly used in the seal industry. CDC was grown in a horizontal tube furnace, shown schematically in Figure 1 under isothermal conditions using Ar-3.5vol \% $\mathrm{Cl}_{2}$ at a superficial flow rate of $0.23 \mathrm{~cm} \mathrm{~s}^{-1}$. Subsequent to the chlorine exposures, the CDC layer thickness on each specimen was determined by optical microscopy on polished surfaces (as shown in Figure 2) for thick layers of CDC, and by scanning electron microscopy using backscattered electrons (as shown in Figure 3 ) for thin layers of CDC.

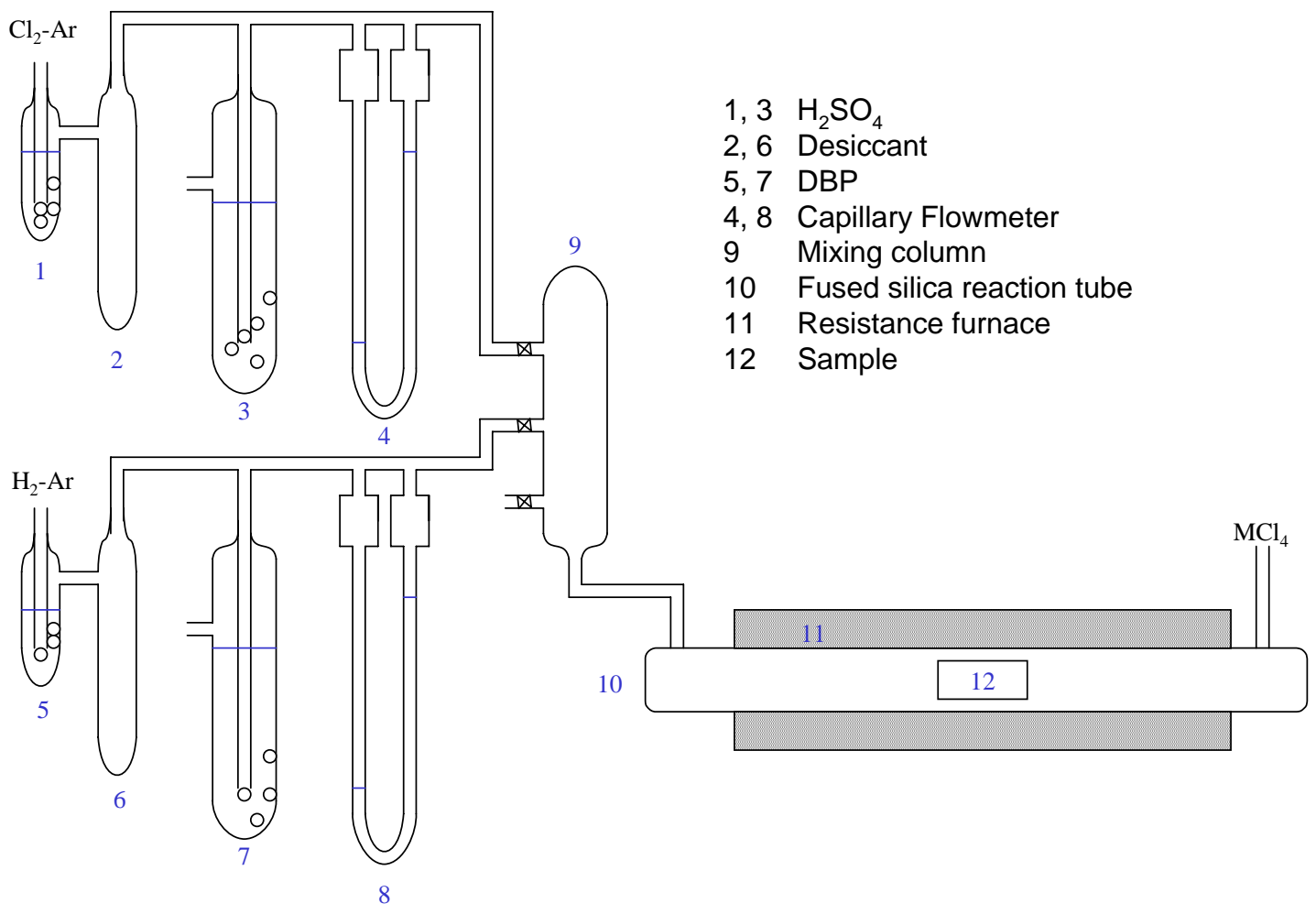

Figure 1. Schematic diagram of horizontal tube furnace and gas flow control system for CDC synthesis on SiC pump seal rings. 


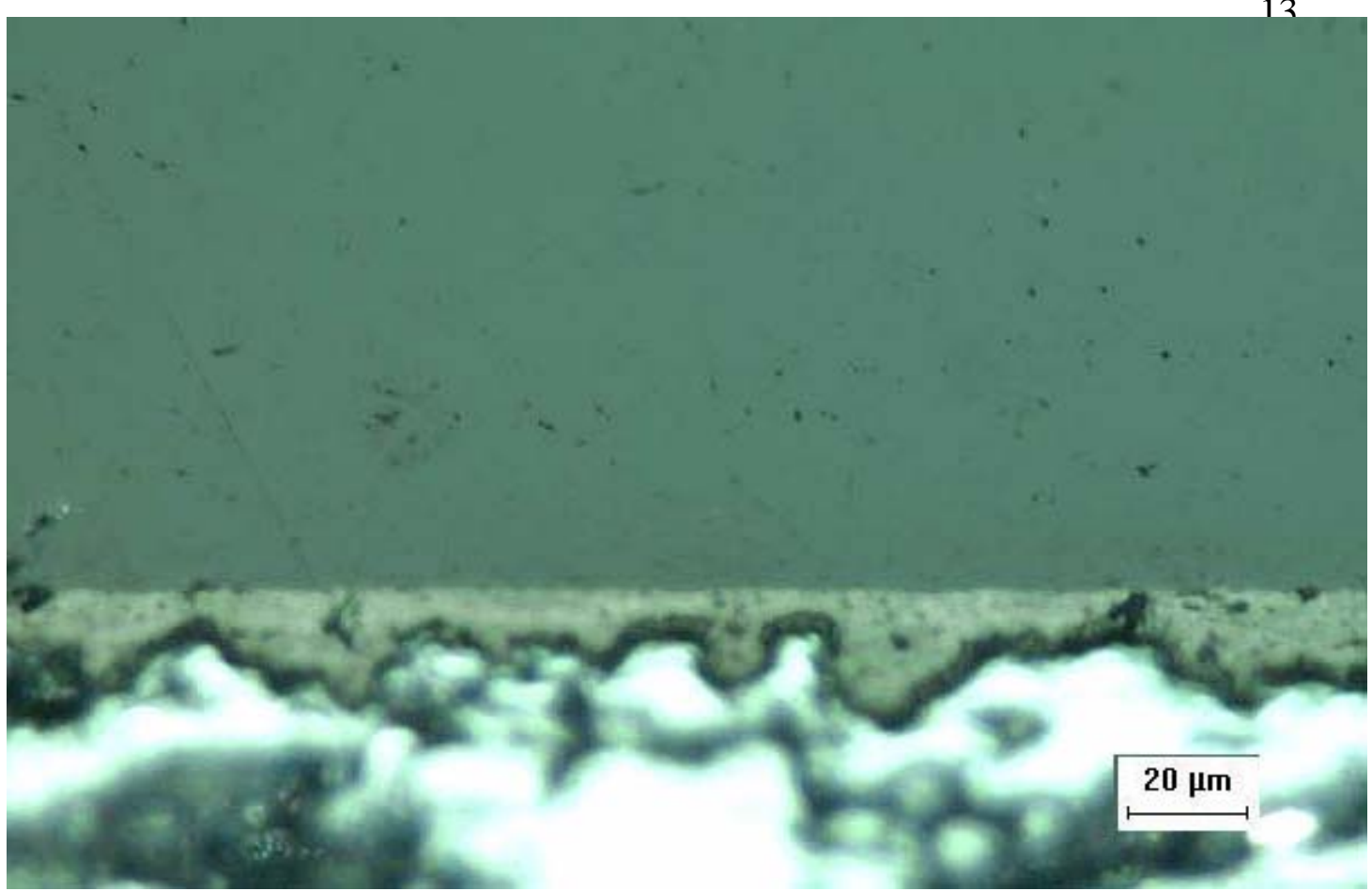

Figure 2. Optical micrograph of CDC layer produced on sintered alpha SiC after one hour treatment in flowing $\mathrm{Ar}-3.5 \% \mathrm{Cl}_{2}$ at $1000^{\circ} \mathrm{C}$. Note the rough interface between the CDC and the $\mathrm{SiC}$, which helps to anchor the layer to the substrate and prevent spallation.

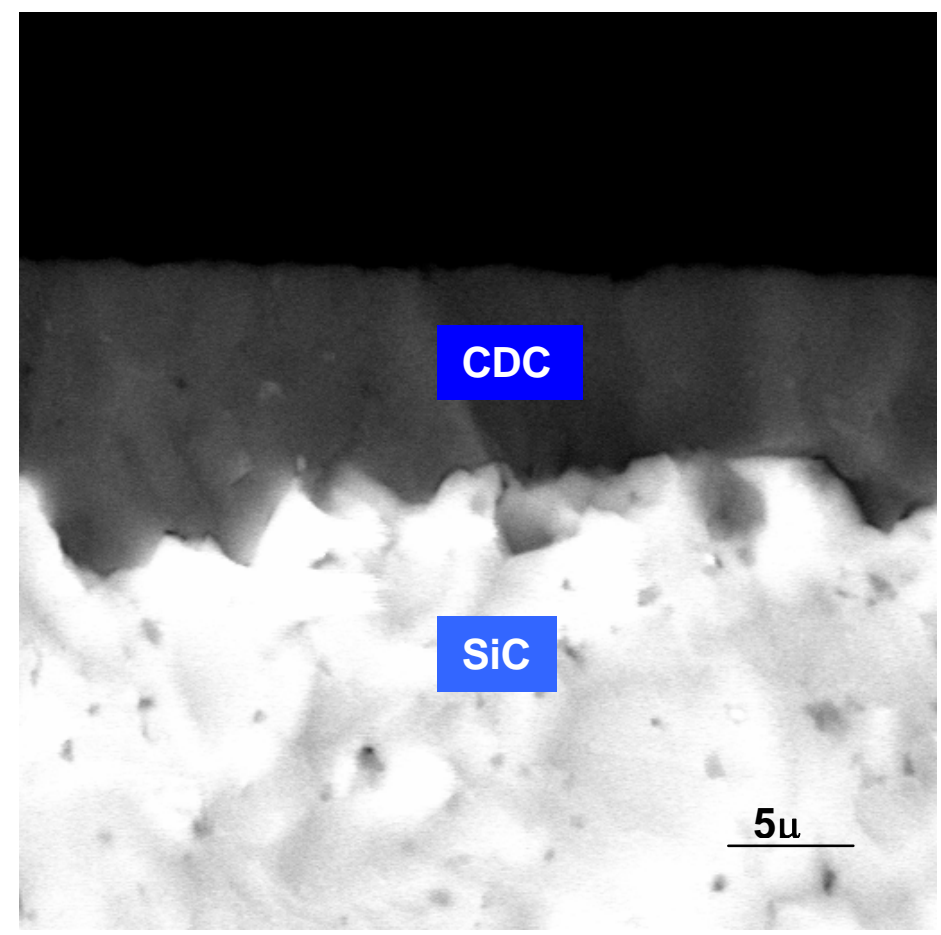

Figure 3. Backscattered Scanning electron micrograph of CDC layer produced on sintered alpha $\mathrm{SiC}$ after one hour treatment in flowing $\mathrm{Ar}-3.5 \% \mathrm{Cl}_{2}$ at $1000^{\circ} \mathrm{C}$. 


\section{i. Parabolic Kinetics}

CDC growth on $\mathrm{SiC}$ specimens generally followed parabolic kinetics as shown in Figure 4 for growth in $\mathrm{Ar}-3.5 \% \mathrm{Cl} 2$ at $1000^{\circ} \mathrm{C}$. Similar kinetics were observed for growth at $900^{\circ} \mathrm{C}$, as shown in Figure 5.

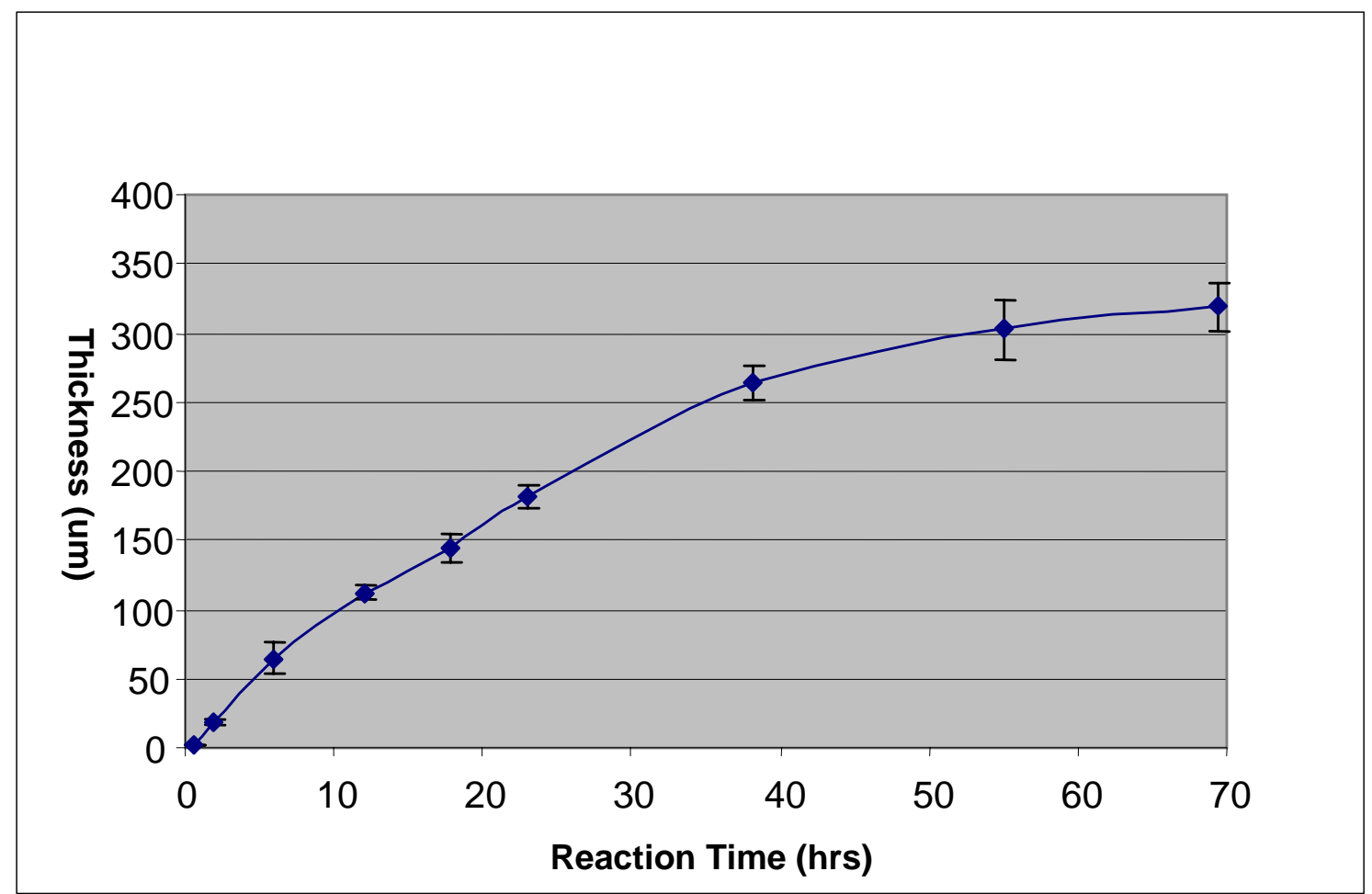

Figure 4. CDC layer thickness versus time for growth on alpha $\mathrm{SiC}$ in $\mathrm{Ar}-3.5 \% \mathrm{Cl}_{2}$ at $1000^{\circ} \mathrm{C}$ 


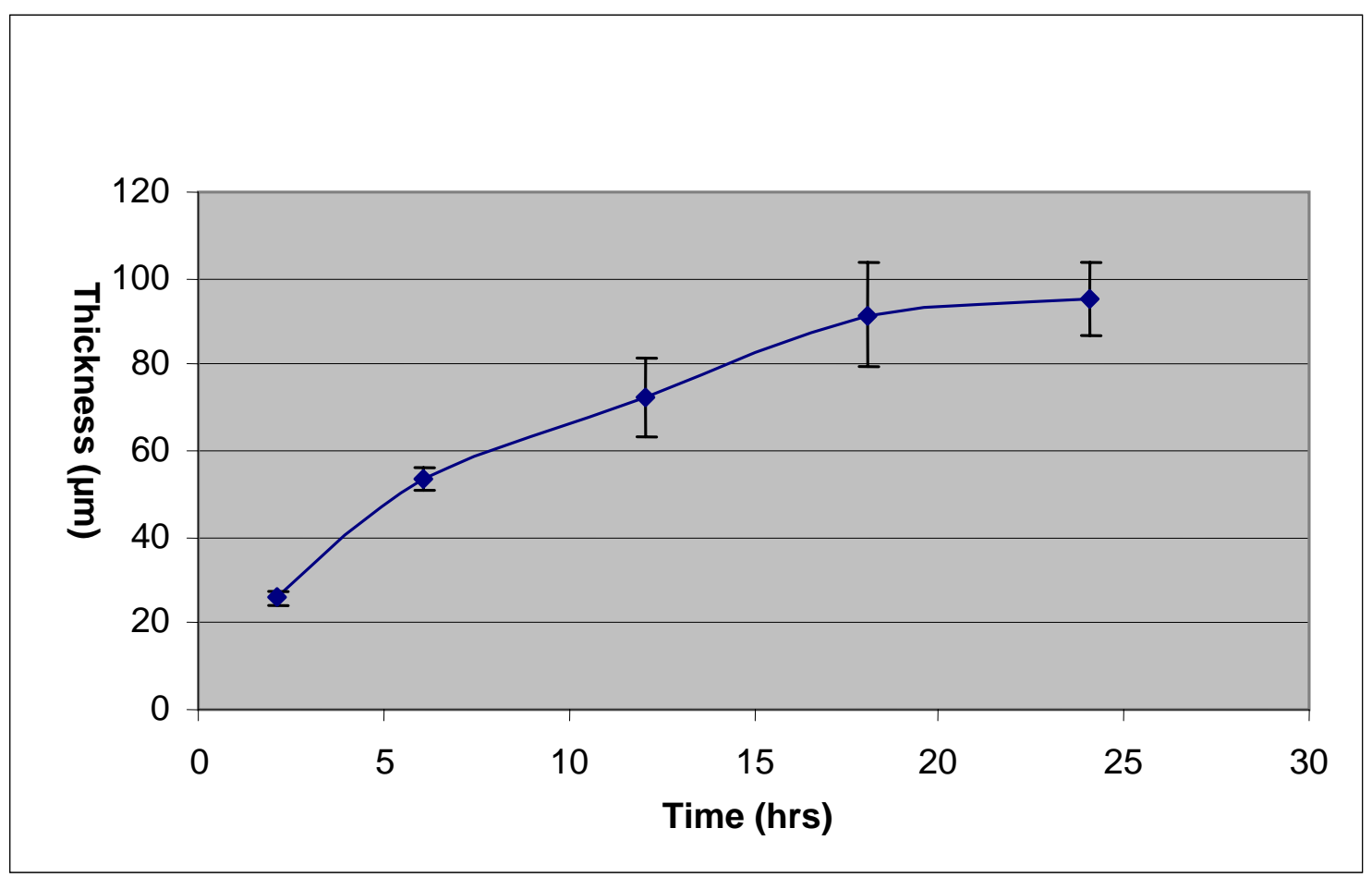
$900^{\circ} \mathrm{C}$

Figure 5. CDC layer thickness versus time for growth on alpha $\mathrm{SiC}$ in $\mathrm{Ar}-3.5 \% \mathrm{Cl}_{2}$ at

The parabolic kinetic rate constants obtained at 900 and $1000^{\circ} \mathrm{C}$ can be fitted to an Arrhenius type equation to predict the temperature dependence of the CDC growth rate in this temperature range. The result can be summarized in Equation 1, which can be used to predict the average thickness of CDC layers formed in this environment as a function of time and temperature.

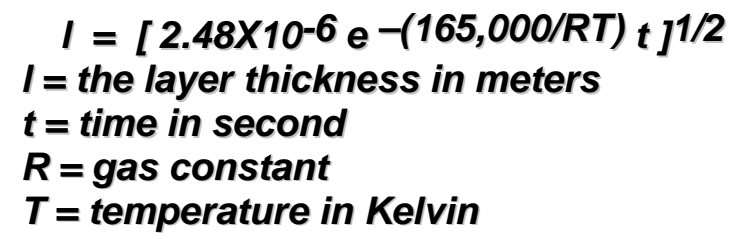$$
I=[2.48 \times 10-6 \text { e }-(165,000 / R T) t]^{1 / 2}
$$$$
I=\text { the layer thickness in meters }
$$$$
t=\text { time in second }
$$$$
R=\text { gas constant }
$$$$
T=\text { temperature in Kelvin }
$$

Equation (1) is valid over a range of gas flow velocities from 0.09 to $0.36 \mathrm{~cm} \mathrm{~s}^{-1}$ at $1000^{\circ} \mathrm{C}$, except when multiple specimens are treated at very low gas velocities when the exposed $\mathrm{SiC}$ surface may be sufficient for consumption of all of the chlorine in the gas stream.

\section{ii. Implications of Parabolic Kinetics}

Parabolic kinetic rate laws for growth of reaction product layers in high temperature corrosion processes are usually associated with reaction rate control by diffusional transport of a reactant or a reactant product through the layer. In the case of CDC, which is known to contain nanoscale porosity, it is reasonable to expect that the transport mechanism is diffusional transport of gas species through the pores. However, the relatively high activation energy in equation (1) of $165,000 \mathrm{~J} / \mathrm{mol}$ would be unusual for a gas phase diffusion process. Furthermore, the average diameter of pores in CDC are smaller than $1.5 \mathrm{~nm}^{11}$, while $\mathrm{SiCl}_{4}$ (the most thermodynamically stable silicon chloride) molecules have a diameter of $0.45 \mathrm{~nm}$, and could not easily penetrate such 
fine pores. This suggests that the reactive species may be transported as adsorbed species on the pore surfaces rather than as gas molecules within the material.

In order to further clarify the mechanism of CDC growth and transport, a cross section view of a CDC layer on $\mathrm{SiC}$ was produced after growth in $\mathrm{Ar}-3.5 \% \mathrm{Cl}_{2}$ for two hours at $900^{\circ} \mathrm{C}$, as shown in Figure 6. The CDC layer on this sample is approximately 10 micrometers thick. X-ray fluorescence microanalysis was performed at locations a through $g$ on the diagram using the scanning electron beam with a spatial accuracy of approximately 1 micrometer. The results were analyzed based on the Scapolite (NU72) reference material, and the variation of chlorine content with position through the CDC layer is shown in Figure 7.

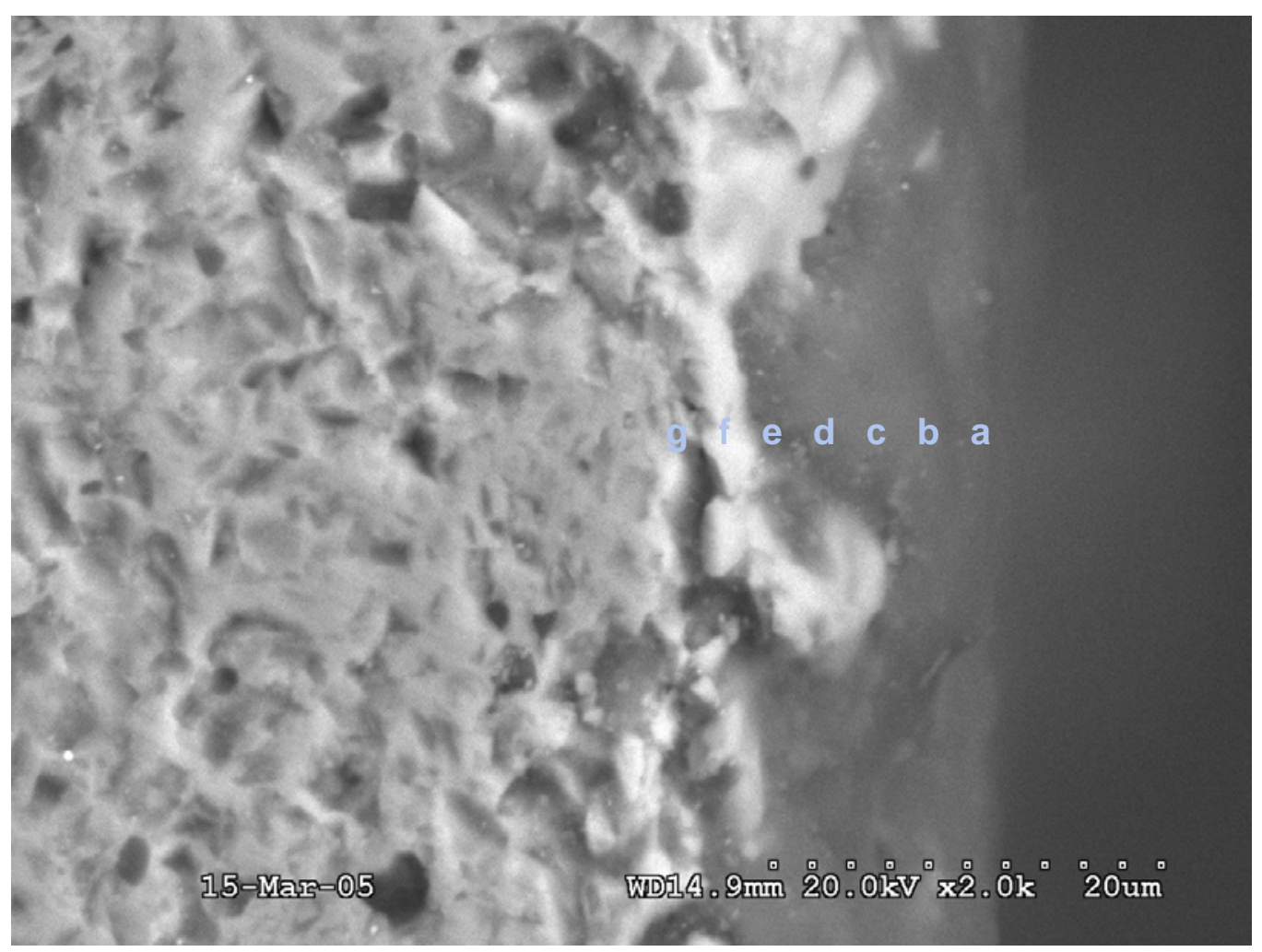

Figure 6. Cross section scanning electron micrograph of CDC layer grown on $\mathrm{SiC}$ in $\mathrm{Ar}-$ $3.5 \% \mathrm{Cl}_{2}$ for two hours at $900^{\circ} \mathrm{C}$. X-ray fluorescence analysis was performed for chlorine at positions $\mathrm{a}-\mathrm{g}$. 


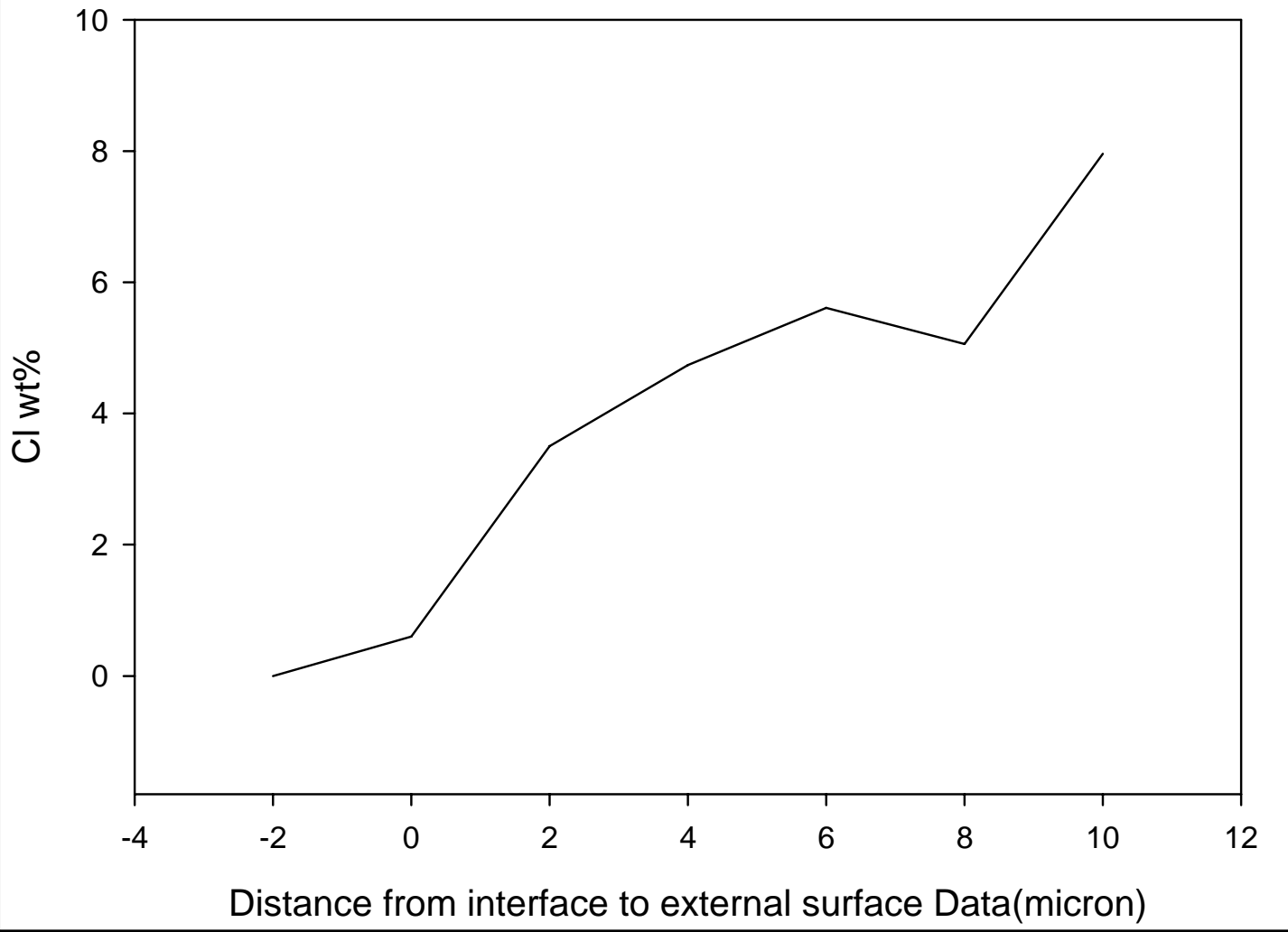

Figure 7. Chlorine concentration in CDC as a function of position within the CDC layer formed on $\mathrm{SiC}$ in $\mathrm{Ar}-3.5 \% \mathrm{Cl}_{2}$ for two hours at $900^{\circ} \mathrm{C}$.

As shown in Figure 7, the chlorine concentration in the CDC decreases continuously from a high value of approximately $8 \%$ at the external surface to nearly zero at the interface with the $\mathrm{SiC}$. This profile is consistent with parabolic growth controlled by transport of chlorine from the reactive atmosphere to the reacting $\mathrm{SiC}$ interface. Based on the apparent activation energy for the rate equation, the chlorine is likely to be transported by surface diffusion along the pore network in the CDC. 


\section{B. CDC Mechanical Properties}

CDC forms rapidly and consistently when $\mathrm{SiC}$ is exposed to flowing $\mathrm{Ar}-3.5 \% \mathrm{Cl}_{2}$ at $1000^{\circ} \mathrm{C}$. Visible light Raman spectroscopy of the treated surface shows large Raman shifts in the vicinity of $1580 \mathrm{~cm}^{-1}$ (G band) and $1340 \mathrm{~cm}^{-1}$ (D band), similar to the spectra obtained from disordered graphite. These spectra are easily distinguished from those of untreated $\mathrm{SiC}$, but the minor constituents of the CDC, including nanocrystalline diamond and fullerenes, are not easily identified by this technique.

Mechanical properties of CDC layers on SiC were determined using nano-indentation with a Berkovich diamond indenter. Indentation procedures were controlled to maintain the indentation depth at less than one to two micrometers, so that indentation characteristics were controlled by the properties of the surface film and not by those of the substrate for CDC layers thicker than 10-20 micrometers. The nano-indentation technique provides a means for simultaneously obtaining both the hardness and elastic modulus of a material from a small indentation. During nano-indentation, the load on the indenter and its displacement into the material are measured simultaneously. A typical load-displacement curve is shown in Figure 8.

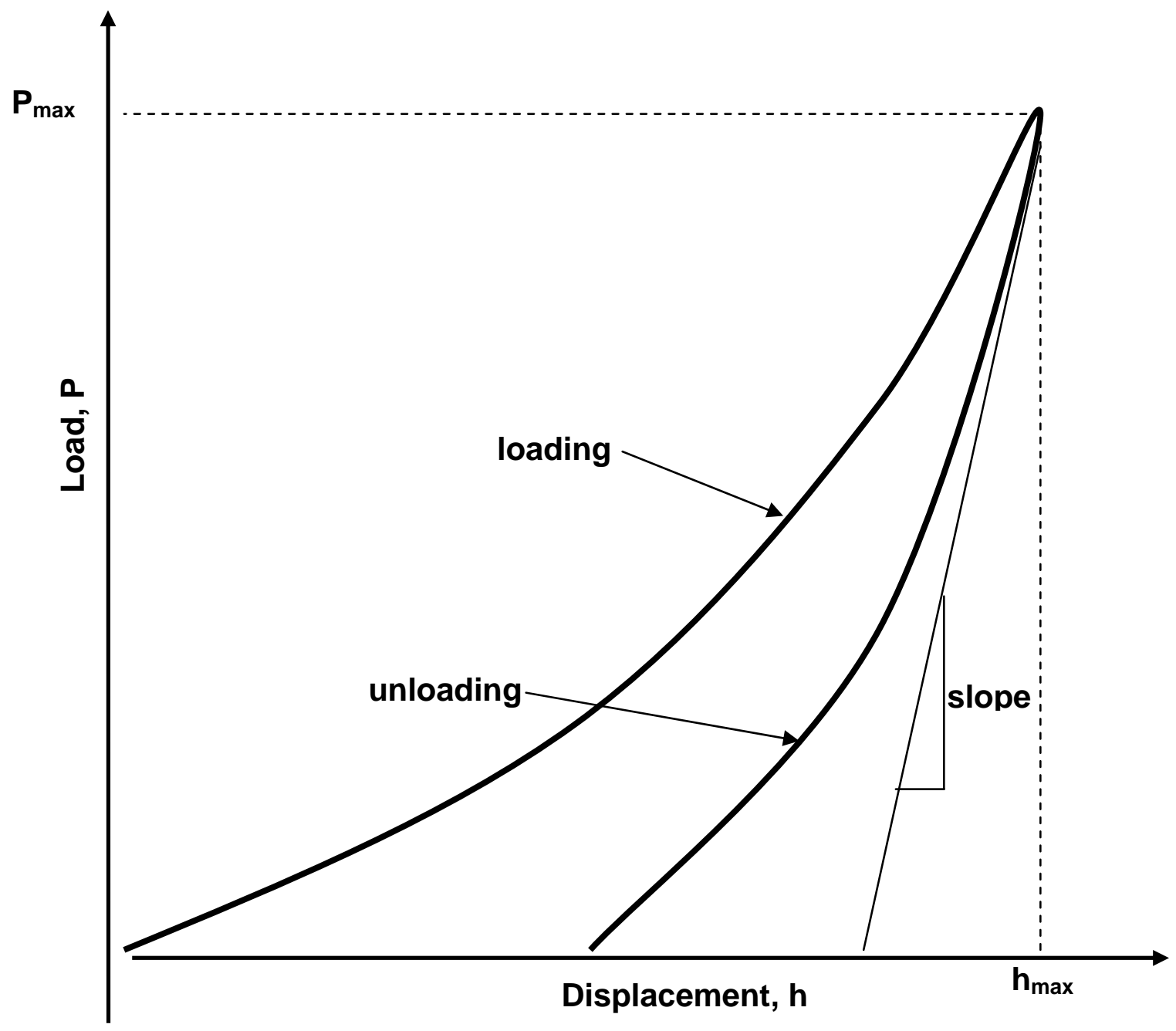

Figure 8. Load-displacement curve for nano-indentation. 
Material properties are obtained from the geometry of the load-displacement curve near the maximum load and penetration. The hardness of the material is defined by equation (2):

$$
\boldsymbol{H}=\boldsymbol{P}_{\max } / \boldsymbol{A}
$$

Where $\mathrm{P}_{\max }$ is the maximum load applied to the indenter and $\mathrm{A}$ is the projected area of the indenter, which can be calculated from the penetration depth and the geometry of the Berkovich diamond. The elastic modulus of the material can be obtained from the slope of the unloading portion of the load-displacement curve near the maximum load, as the elastic strain in the material relaxes during the initial unloading. Equation (3) gives the elastic modulus:

$$
E_{r}=\frac{\sqrt{ } \pi}{2 \beta} \frac{S}{\sqrt{A}}
$$

Where $S$ is the slope of the load displacement curve indicated in Figure $8, \beta$ is a constant equal to 1.034 for the Berkovich indenter.

CDC films grown by one-hour treatments in $\mathrm{Ar}-3.5 \% \mathrm{Cl}_{2}$ at $1000^{\circ} \mathrm{C}$ had a mean hardness of 1.0 GPa and a mean elastic modulus of $15 \mathrm{GPa}$ with little variation from one run to another. The standard deviation in hardness and elastic modulus in tests performed on each specimen was in the range of 0.2 to 0.5 of the mean value, probably due to the surface roughening that accompanied the conversion reaction. The mean hardness appeared to decrease slightly when the treatment time was increased up to 25 hours, however this was within the range of the scatter in the individual measurements and may have reflected increased surface porosity.

When the treatment temperature is reduced to $900^{\circ} \mathrm{C}$, the apparent hardness of the CDC layer is increased by approximately a factor of two for short treatments times ( 2 hours or less), but the properties of CDC layers produced after longer treatments times are similar to those formed at $1000^{\circ} \mathrm{C}$. Earlier work indicating that the hardness of CDC could be increased by converting the $\mathrm{SiC}$ in a $\mathrm{Cl}_{2} / \mathrm{H}_{2}$ gas mixture was confirmed in this study, with gas mixtures containing $\mathrm{Cl}_{2} / \mathrm{H}_{2}$ gases in a ratio of 1:0.37 producing CDC with hardness ranging from 1.6 to 4.7 $\mathrm{GPa}$, and having similar variability as was observed in gases containing only chlorine as a reactive specie. Reducing the conversion temperature when chlorine was present had a synergistic effect on the hardness, with hardness values ranging between 6 and $9.5 \mathrm{GPa}$ for CDC produced in $\mathrm{Cl}_{2} / \mathrm{H}_{2}$ gas blends of 1:0.25 at $900^{\circ} \mathrm{C}$.

When chlorine and hydrogen mix in the gas phase, they react to form $\mathrm{HCl}$ according to reaction (2)

$$
\mathrm{Cl}_{2}+\mathrm{H}_{2}=2 \mathrm{HCl}
$$

Therefore, it is likely that the effects of hydrogen additions to chlorine could be duplicated by adding $\mathrm{HCl}$ instead. Gas mixtures of $\mathrm{Cl}_{2} / \mathrm{HCl}$ in ratios of $1 / 0.5$ to $1 / 4$ were used to produce $\mathrm{CDC}$ on $\mathrm{SiC}$ in 2 hour treatments at $1000^{\circ} \mathrm{C}$. As shown in Figure 9, the maximum hardness of approximately 2.4 GPa was obtained for a $\mathrm{Cl}_{2} / \mathrm{HCl}$ ratio of $1 / 2$.

In addition to obtaining high hardness, the gas mixtures containing $\mathrm{HCl}$ also had the advantage of more consistent properties with smaller standard deviations in hardness than was observed in $\mathrm{Cl}_{2} / \mathrm{H}_{2}$ gas mixtures. This characteristic can be partially explained by the smoother surface observed for $\mathrm{CDC}$ produced in $\mathrm{Cl}_{2} / \mathrm{HCl}$ mixtures than in the other gas mixtures used. Figure 10 compares the surface structures of CDC layers formed after two-hour treatments in Ar- 
3.5\% $\mathrm{Cl}_{2}$ and in $\mathrm{Cl}_{2} / \mathrm{H}_{2}$ and $\mathrm{Cl}_{2} / \mathrm{HCl}$ gas mixtures. The roughness of the $\mathrm{CDC}$ formed in the $\mathrm{Cl}_{2} / \mathrm{HCl}$ gas mixture is clearly smaller than those of the CDC formed in the other two environments.

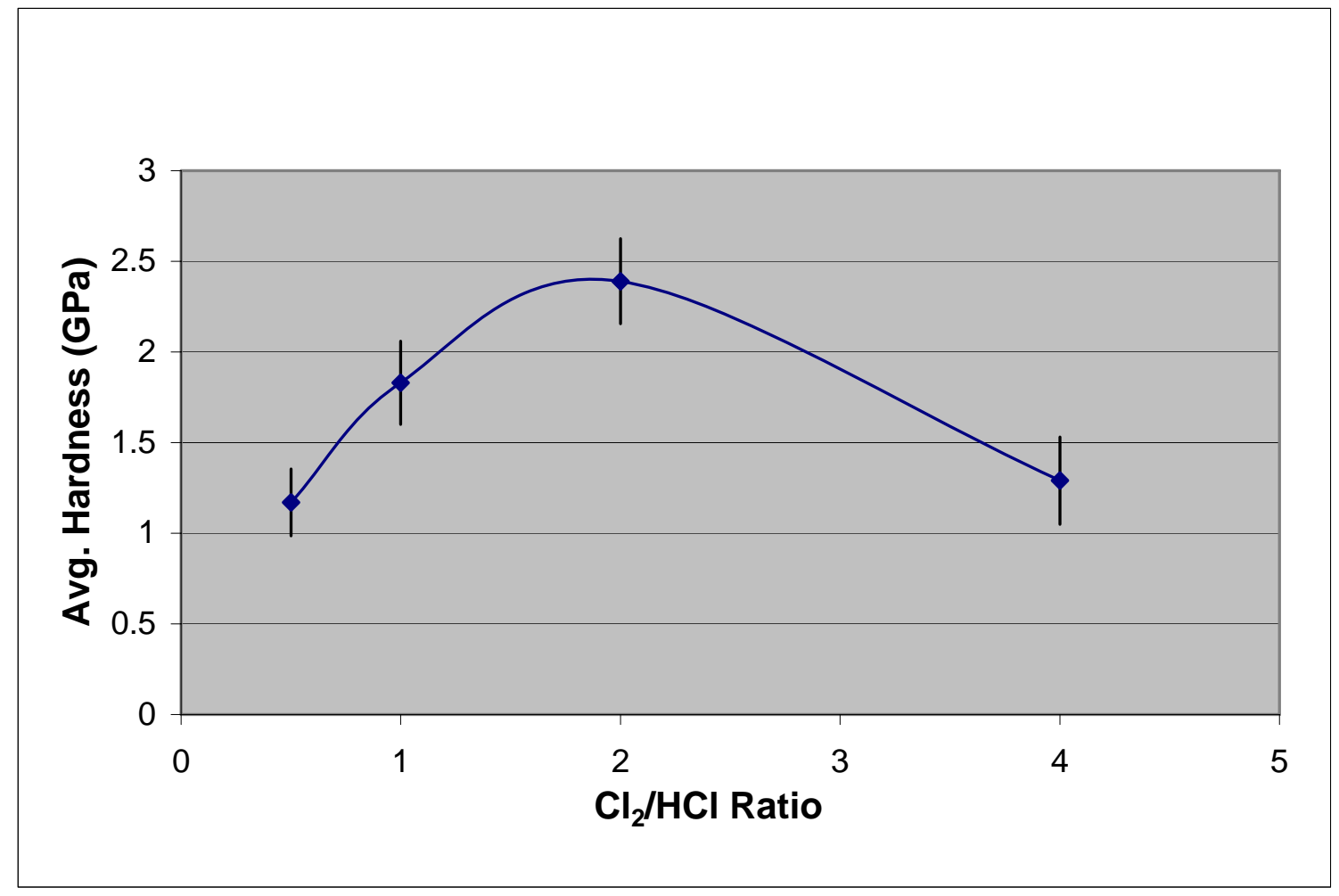

Figure 9. Hardness of CDC produced on $\mathrm{SiC}$ by treatment in $\mathrm{Cl}_{2} / \mathrm{HCl}$ gas mixtures at $1000^{\circ} \mathrm{C}$ as a function of $\mathrm{Cl}_{2} / \mathrm{HCl}$ ratio.

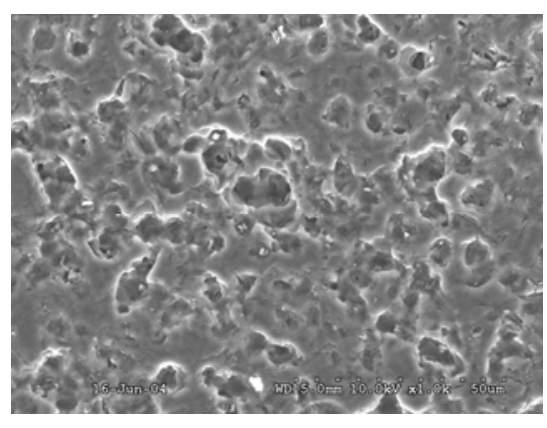

(a)

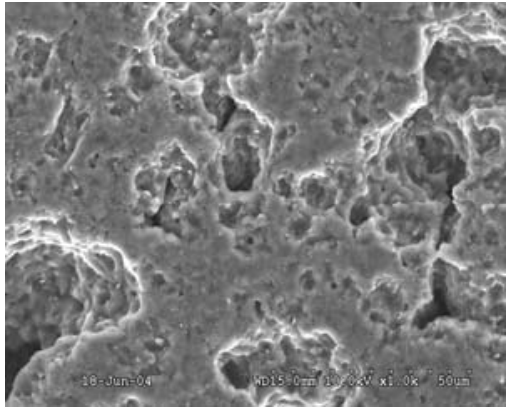

(b)

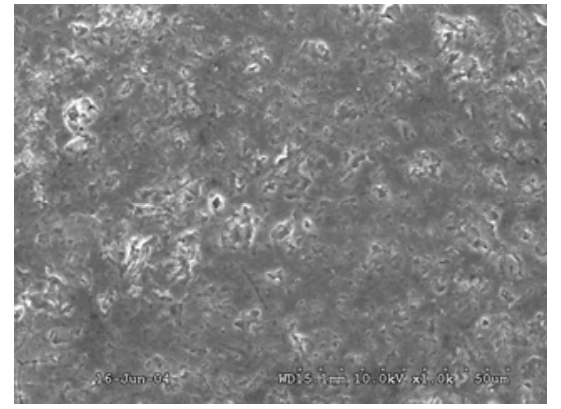

(c)

Figure 10. Scanning electron micrographs of CDC surfaces produced in (a) $\mathrm{Ar}-3.5 \% \mathrm{Cl}_{2}$ two hour treatment at $1000^{\circ} \mathrm{C}$. (b) $\mathrm{Cl}_{2} / \mathrm{H}_{2}$ ratio of $1 / 0.37$ two hour treatment at $1000^{\circ} \mathrm{C}$. (c) $\mathrm{Cl}_{2} / \mathrm{HCl}$ ratio of $1 / 0.5$ one hour treatment at $1000^{\circ} \mathrm{C}$. 


\section{Effects of Post-Synthesis Treatments in Hydrogen on Properties of CDC}

In its as-synthesized state, CDC contains a quantity of residual chlorine, resulting from the chlorination treatment of the $\mathrm{SiC}$ substrate. In some applications, this residual chlorine could produce detrimental effects. The chlorine content of CDC was analyzed in an JEOL JXA-733 electron microprobe using wavelength dispersive X-ray emission spectrometry with scapolite (NU72) as a standard. It was determined that $90 \%$ or more of the residual chlorine could be removed from the CDC by a heat treatment in flowing $\mathrm{Ar}-5 \% \mathrm{H}_{2}$ for 8 hours at $800^{\circ} \mathrm{C}$. Because $800^{\circ} \mathrm{C}$ is below the synthesis temperature for $\mathrm{CDC}$ on $\mathrm{SiC}$, the hydrogen treatment was not expected to affect the physical properties of the CDC to a significant extent. Table I shows the hardness and chlorine content of several CDC specimens before and after hydrogen treatment demonstrating that chlorine is removed with minimal change in the hardness of the CDC. Treatment in pure $\mathrm{Ar}$ or $\mathrm{N}_{2}$ for similar times and temperatures produced a small $(<25 \%)$ reduction in the chlorine content of the CDC, and also had little effect on the hardness of the material.

\section{Table I. Effects of Post-Synthesis Hydrogen Treatment on Residual Chlorine Content and Hardness of CDC on SiC.}

\begin{tabular}{|c|c|l|l|l|}
\hline $\begin{array}{l}\text { Synthesis } \\
\text { Condition }\end{array}$ & $\begin{array}{l}\text { As-Synthesized } \\
\text { Chlorine Conc. } \\
\text { (wt \%) }\end{array}$ & $\begin{array}{l}\text { Mean } \\
\text { Hardness } \\
(\mathrm{GPa})\end{array}$ & $\begin{array}{l}\text { Treated } \\
\text { Chlorine } \\
\text { Conc. (wt\%) }\end{array}$ & $\begin{array}{l}\text { Treated } \\
\text { Hardness } \\
(\mathrm{GPa})\end{array}$ \\
\hline $\begin{array}{c}2 \mathrm{hrs} @ 1000^{\circ} \mathrm{C} \\
\text { in } \mathrm{Ar}-3.5 \% \mathrm{Cl}_{2}\end{array}$ & 3.2 & 1.65 & 0.1 & 1.52 \\
\hline $\begin{array}{c}1 \mathrm{hr} @ 1000^{\circ} \mathrm{C} \\
\text { in } 2 / 1 \mathrm{Cl} / \mathrm{HCl}\end{array}$ & 3.0 & 2.4 & 0.2 & 2.2 \\
\hline
\end{tabular}

Hydrogen treatment of the synthesized CDC removed nearly all of the residual chlorine and had minimal effect on the hardness of the material. This treatment also significantly affected the tribological properties of the CDC, and was the subject of a patent disclosure described later in this report.

\section{Tribological Performance of CDC}

Improved tribological performance of CDC treated $\mathrm{SiC}$ compared with untreated $\mathrm{SiC}$ was determined using a CSEM pin-on-disk tribometer at Argonne National Laboratory. The tribometer measured the ratio of lateral to normal force (Coefficient of Friction) when a flat surface is rotated against a stationary pin or ball. In these experiments, the stationary pin was a silicon nitride ball 3/8" in diameter with a normal dead load of 1 to $10 \mathrm{~N}$, and the rotation rate of the disk was 50 to $500 \mathrm{rpm}$.

The friction coefficient of CDC treated $\mathrm{SiC}$ under these conditions is typically reduced from the range of 0.6 to 0.7 for untreated $\mathrm{SiC}$ to the range of 0.2 to 0.3 , as shown in Figure 11 for an experiment on CDC produced by a one-hour treatment in $\mathrm{Ar}-3.5 \% \mathrm{Cl}_{2}$ at $1000^{\circ} \mathrm{C}$. The friction 
coefficient rises with time during a short initial transient period, but then stabilizes at a value between 0.23 and 0.24 .

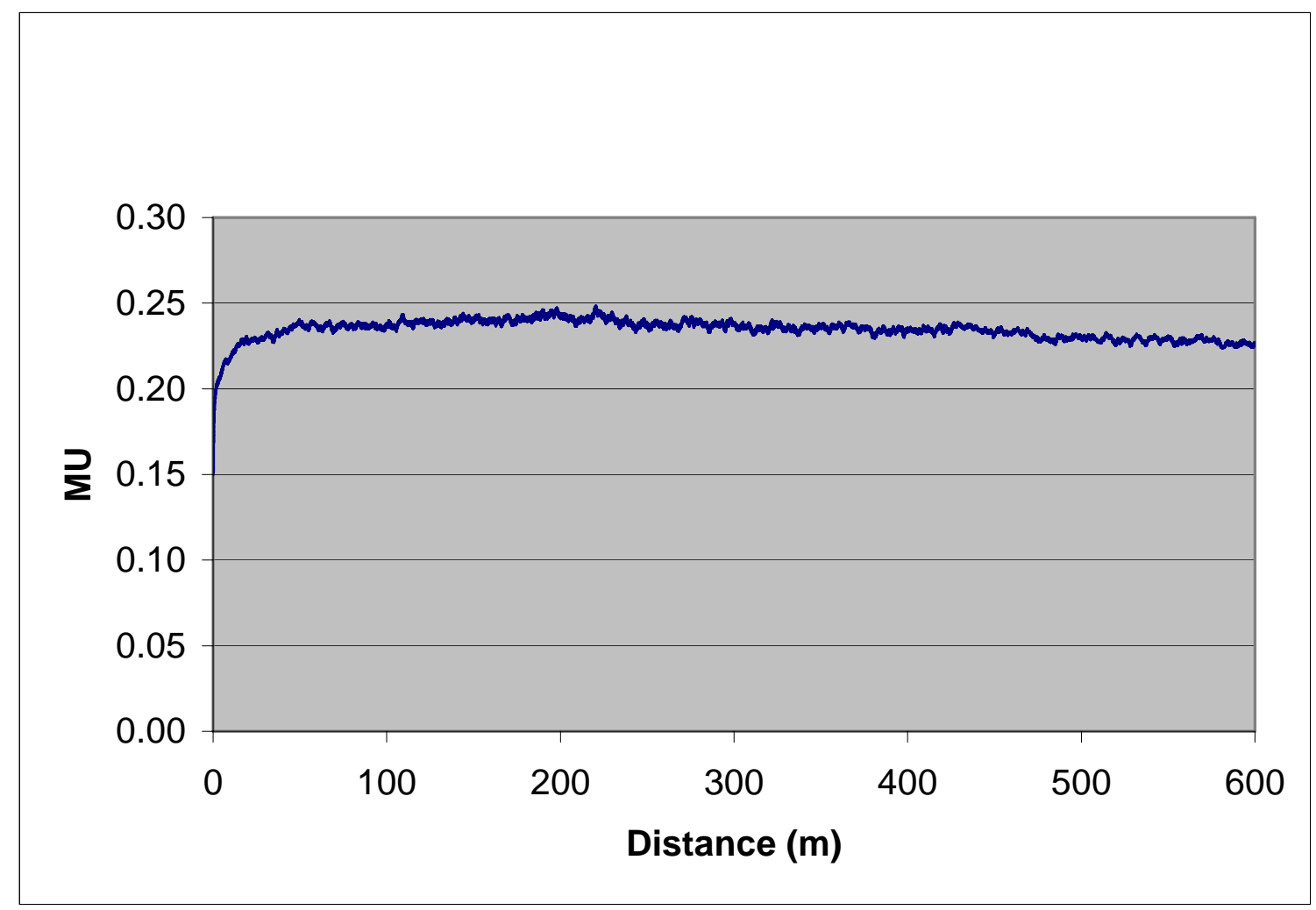

Figure 11 Friction coefficient versus sliding distance in pin-on-disk test on CDC produced on $\mathrm{SiC}$ by one-hour treatment in $\mathrm{Ar}-3.5 \% \mathrm{Cl}_{2}$ at $1000^{\circ} \mathrm{C}$. Normal load, $5 \mathrm{~N}$, rotation rate, $500 \mathrm{rpm}$.

Friction coefficients for CDC produced in $\mathrm{Ar}-3.5 \% \mathrm{Cl}_{2}$ were quite reproducible, and were not strongly affected by either the time or the temperature of the treatment as indicated by the results shown in Figure 12 for CDC formed by 8 hour and 16 hour treatments at $900^{\circ} \mathrm{C}$. Both treatments produce friction coefficients in the range of 0.2 to 0.25 after an initial transient period. 


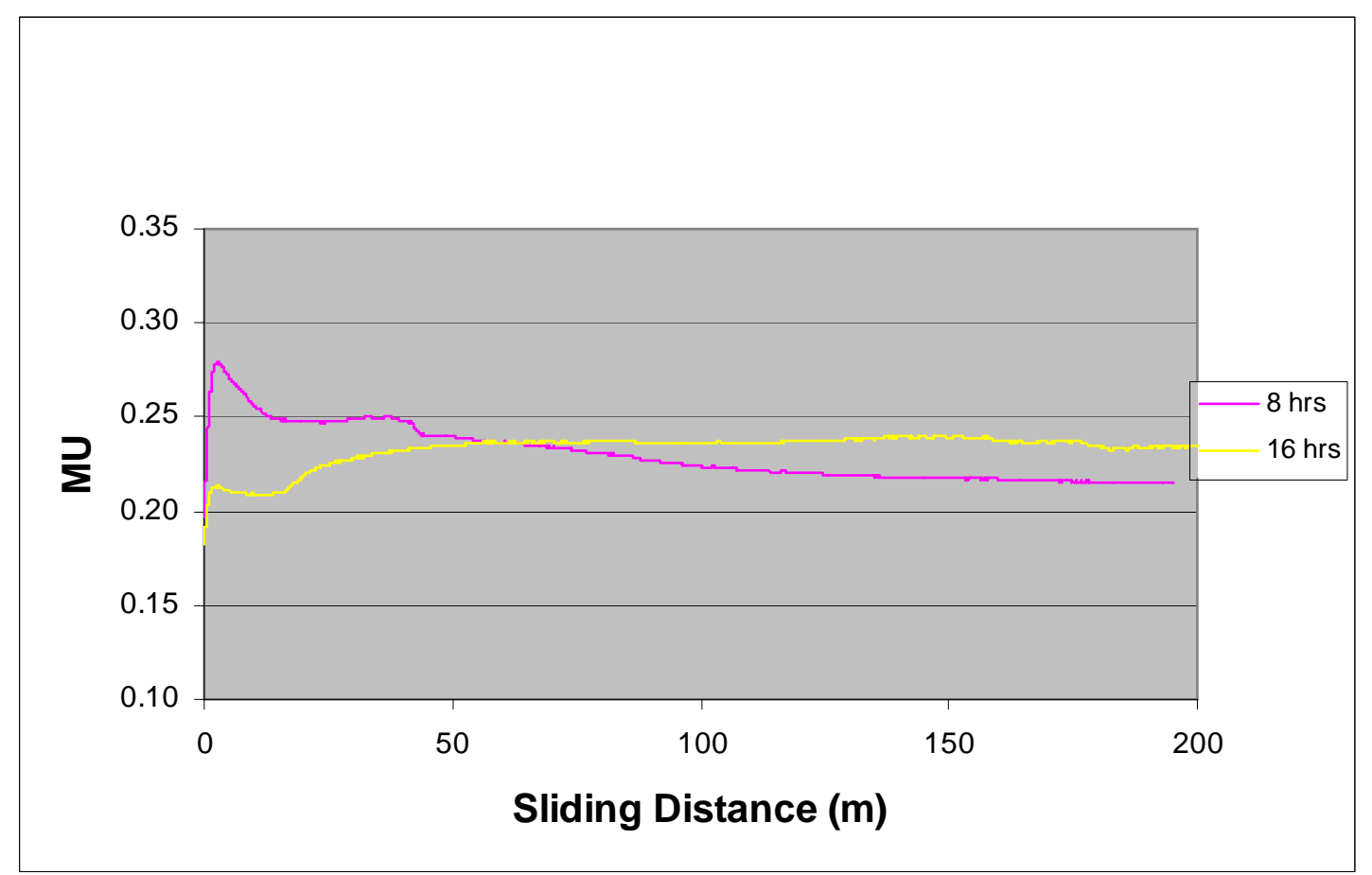

Figure 12. Friction coefficients versus sliding distance in pin-on-disk tests on CDC produced on $\mathrm{SiC}$ by eight and sixteen hour treatments in $\mathrm{Ar}-3.5 \% \mathrm{Cl}_{2}$ at $900^{\circ} \mathrm{C}$. Normal load, $5 \mathrm{~N}$, rotation rate, $200 \mathrm{rpm}$.

\section{E. Effects of Surface Polishing on Tribological Performance of CDC}

Because the as-grown CDC surface is rough in comparison to the unreacted $\mathrm{SiC}$, the friction coefficient in the early stages of the tribology test may be affected by surface roughness more than by the material properties. Figure 13 shows the friction coefficient versus sliding distance for CDC grown in $\mathrm{Ar}-12 \% \mathrm{Cl}_{2}-4.5 \% \mathrm{H}_{2}$ for three hours at $1100^{\circ} \mathrm{C}$ in the as-grown state and after polishing to a 1 micrometer finish with alumina polishing compound. After an initial transient, the friction coefficient of the polished CDC is approximately $49 \%$ lower than that of the unpolished CDC. 


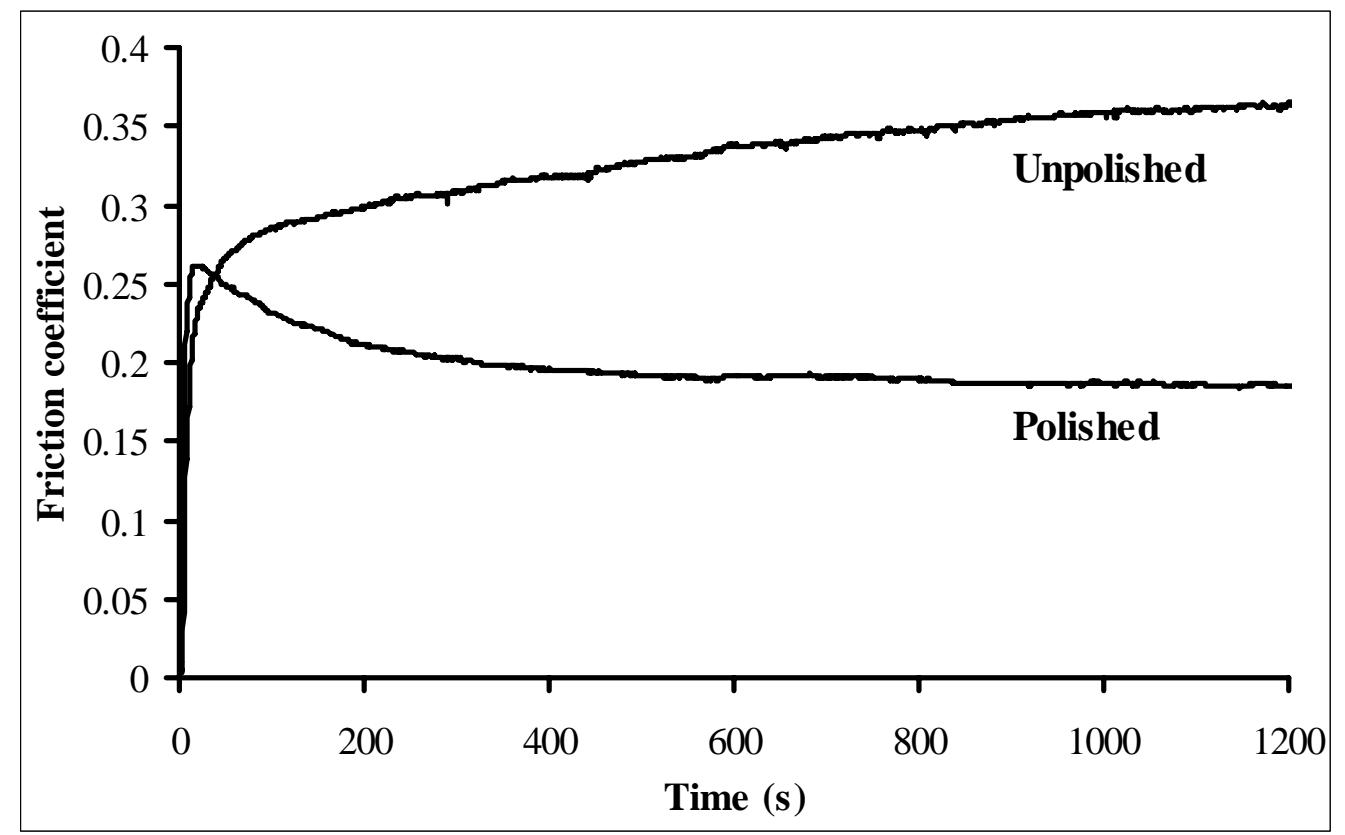

Figure 13. Friction coefficient versus time for CDC grown in $\mathrm{Ar}-12 \% \mathrm{Cl}_{2}-4.5 \% \mathrm{H}_{2}$ for three hours at $1100^{\circ} \mathrm{C}$. The effect of surface polishing is illustrated. The polished surface has approximately $40 \%$ lower friction coefficient after the initial transient dies out. 
Modifications of the chlorination environment to change the physical properties of the CDC also affect the friction performance of the material. Gas mixtures containing both $\mathrm{Cl}_{2}$ and $\mathrm{H}_{2}$ raise the hardness of the CDC, but result in reproducibility problems from one specimen to another. This irreproducibility is also reflected in the friction performance of the CDC synthesized in these environments, as indicated in Figure 14. Figure 14 shows friction coefficient versus sliding distance for three CDC coatings synthesized in a gas mixture with a $\mathrm{Cl}_{2} / \mathrm{H}_{2}$ ratio of $1 / 0.25$ at $900^{\circ} \mathrm{C}$. While one sample showed a friction coefficient of approximately 0.24 , consistent with the results obtained in the $\mathrm{Ar}^{-\mathrm{Cl}_{2}}$ gas mixture, the other two showed friction coefficients on the order of 0.4 , a high value for CDC.

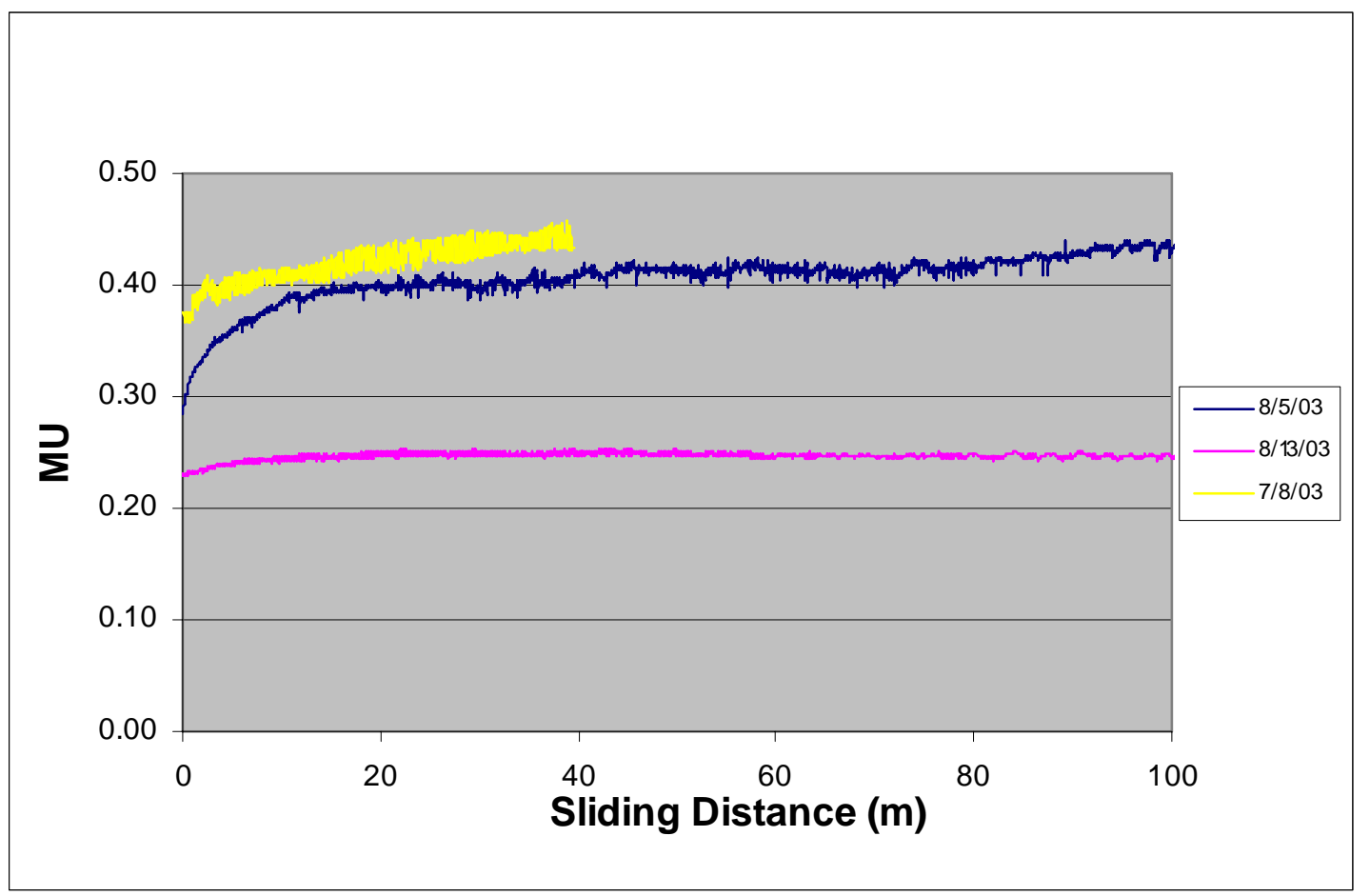

Figure 14. Friction coefficients versus sliding distance in pin-on-disk tests on CDC produced on $\mathrm{SiC}$ by six hour treatments in $\mathrm{Cl}_{2} / \mathrm{H}_{2}$ mixture in ratio of $1 / 0.25$ at $900^{\circ} \mathrm{C}$. Normal load, $5 \mathrm{~N}$, rotation rate, $200 \mathrm{rpm}$.

As with hardness measurements, more consistent results were obtained in $\mathrm{Cl}_{2} / \mathrm{HCl}$ gas mixtures than in $\mathrm{Cl}_{2} / \mathrm{H}_{2}$ mixtures. Figure 15 shows friction coefficient results for CDC produced in a $\mathrm{Cl}_{2} / \mathrm{HCl}$ gas mixture with a ratio of $1 / 0.5$ at $1000^{\circ} \mathrm{C}$ at different treatment times. Although the one-hour treatment produced the lowest friction coefficient, all of the friction coefficients are below 0.3 , and change little with increasing sliding distance.

\section{F. Effects of post-synthesis hydrogen treatment on friction}

Treatment of the $\mathrm{CDC}$ in $\mathrm{Ar}-5 \% \mathrm{H}_{2}$ at $800^{\circ} \mathrm{C}$ for 8 hours to reduce its chlorine concentration also had the effect of reducing the friction coefficient in subsequent pin-on-disk testing. Figure 16 shows the effect of hydrogen treatment on the friction coefficient on CDC produced in a $\mathrm{Cl}_{2} / \mathrm{H}_{2}$ mixture in ratio of $1 / 0.25$ at $900^{\circ} \mathrm{C}$ and after post-synthesis treatment of the same CDC in $\mathrm{Ar}-5 \% \mathrm{H} 2$ for 8 hours at $800^{\circ} \mathrm{C}$. In this case, the friction coefficient was reduced by approximately a factor of two by the hydrogen treatment, and the friction coefficient of the 
hydrogen treated CDC continues to decrease with increasing sliding distance. In general, the hydrogen treatment consistently reduces the friction coefficient of the CDC in pin-on-disk tests, although the relative reduction in friction coefficient is smaller for CDC layers synthesized under conditions where the as-synthesized friction coefficient was below 0.2.

The presence of hydrogen in the post-synthesis treatment environment is necessary to produce the reduction in friction coefficient. Treatments for similar times and temperatures in $\mathrm{Ar}$ or $\mathrm{N}_{2}$ environments had little effect on the friction coefficient. A provisional patent on the postsynthesis treatment of CDC in hydrogen containing environments to reduce the friction coefficient has been filed.

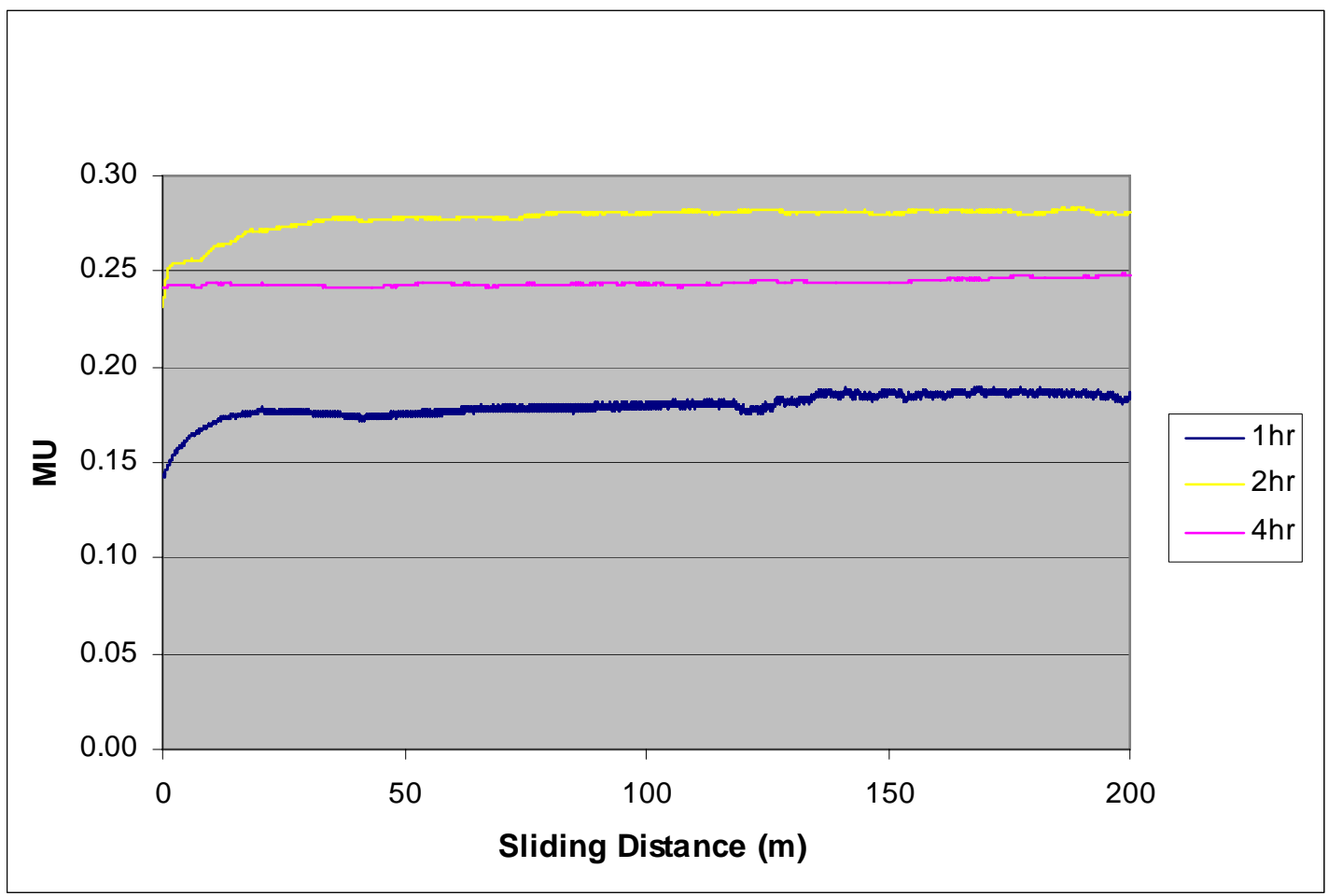

Figure 15. Friction coefficients versus sliding distance in pin-on-disk tests on CDC produced on $\mathrm{SiC}$ by one, two, and four hour treatments in $\mathrm{Cl}_{2} / \mathrm{HCl}$ mixture in ratio of $1 / 0.5$ at $1000^{\circ} \mathrm{C}$. Normal load, $5 \mathrm{~N}$, rotation rate, $200 \mathrm{rpm}$. 


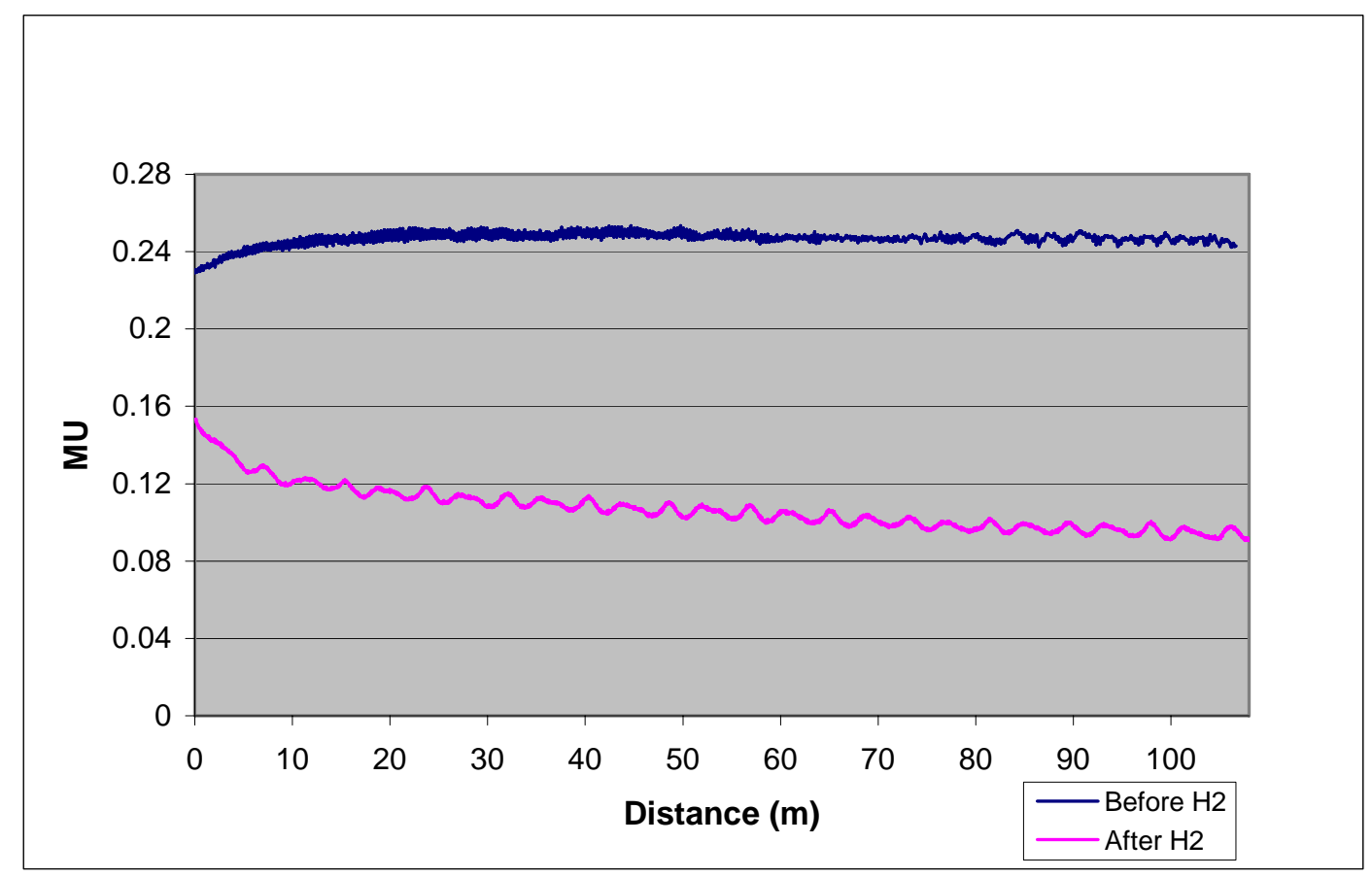

Figure 16. Friction coefficients versus sliding distance in pin-on-disk tests on CDC produced on SiC by 6 hour treatment in $\mathrm{Cl}_{2} / \mathrm{H}_{2}$ mixture in ratio of $1 / 0.25$ at $900^{\circ} \mathrm{C}$ and after postsynthesis treatment of the same CDC in $\mathrm{Ar}-5 \% \mathrm{H} 2$ for 8 hours at $800^{\circ} \mathrm{C}$. Normal load, $5 \mathrm{~N}$, rotation rate, $200 \mathrm{rpm}$.

The performance of the hydrogen treated CDC is also affected by the test environment, with lower friction coefficients being produced in dry environments than in humid laboratory air. Figure 17 shows the friction coefficients as a function of time for CDC with and without hydrogen post treatment in laboratory air and in dry nitrogen. The lowest friction coefficients are obtained for hydrogen post-treated CDC tested in dry nitrogen.

In long duration testing, the performance of hydrogen treated CDC is even better. Figure 18 shows the friction coefficient as a function of time when the test was extended up to six hours. 


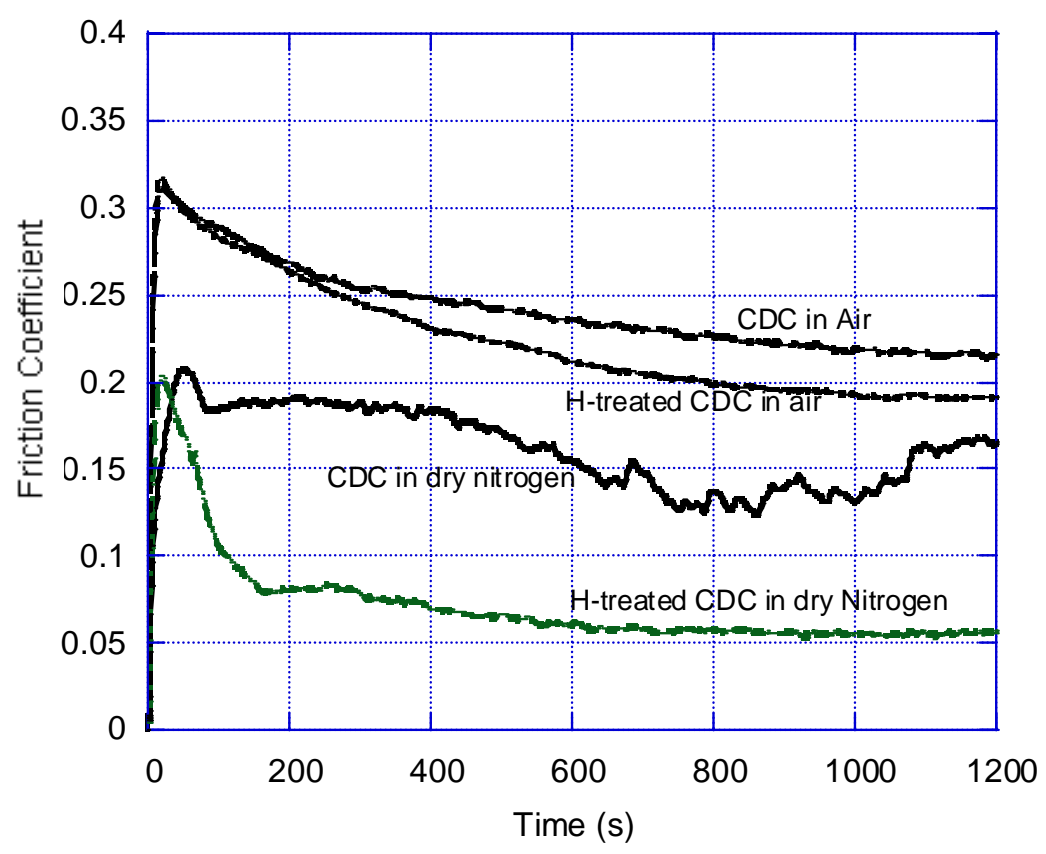

Figure 17. Friction coefficient versus testing time during pin-on-disk testing of CDC with and without hydrogen post treatment, tested in laboratory air and in dry nitrogen. The friction coefficient in dry nitrogen decreases to approximately 0.05 when hydrogen treated CDC is tested in dry nitrogen.

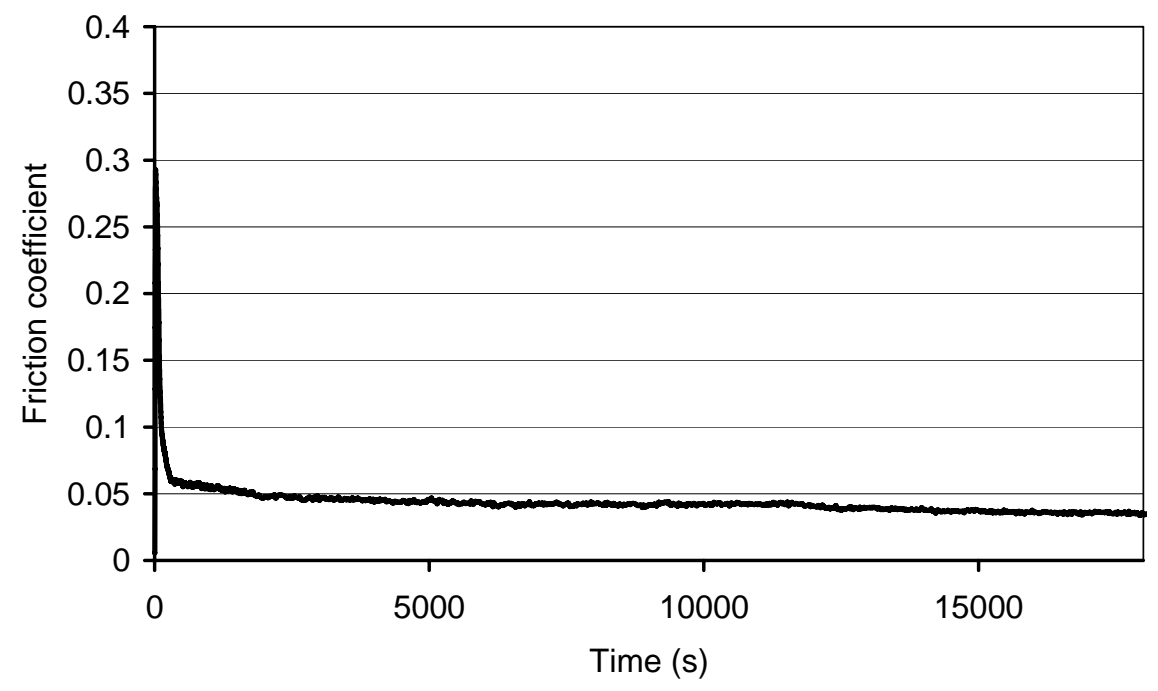

Figure 18. Friction coefficient versus test time for hydrogen treated CDC. Test extended for 5 hours duration, with friction coefficient falling below 0.04 . 


\section{G. Wear of CDC in pin-on-disk tests}

The wear rate of CDC in the context of pin-on-disk tests can be determined by measuring the depth of the wear track produced by the silicon nitride ball on the CDC surface using a noncontact optical profilometer. The geometry of the wear groove can be approximated as a trapezoid, and the volume of material removed can be calculated by multiplying the trapezoidal area by the circumference of the wear track. In order to determine the wear rate of CDC in such experiments, a $\mathrm{SiC}$ plate was treated in $\mathrm{Ar}-3.5 \% \mathrm{Cl}_{2}$ for 31 hours at $1000^{\circ} \mathrm{C}$ to produce a thick CDC layer, which would not wear through even in long-term experiments. This specimen was subjected to pin-on-disk testing at a load of $5 \mathrm{~N}$ in a series of tests with increasing duration ranging from $260 \mathrm{~m}$ to $1360 \mathrm{~m}$ total sliding distance and closely spaced diameters with an average sliding velocity of $14.7 \mathrm{~cm} / \mathrm{s}$. Figure 19 shows that the friction coefficients in these tests were consistently in the range of $0.1-0.12$.

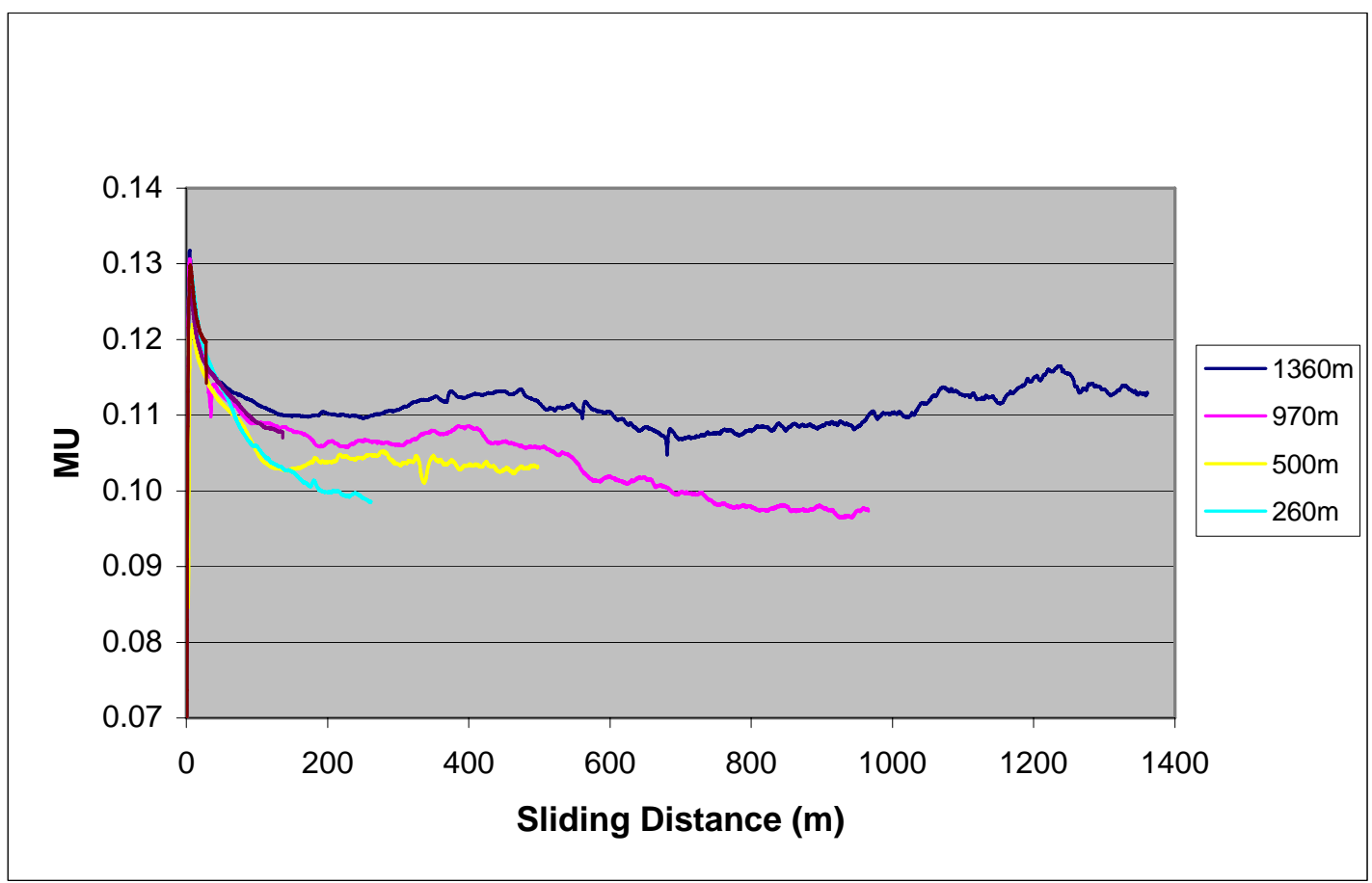

Figure 19. Friction coefficient versus sliding distance in pin-on-disk test on CDC produced on $\mathrm{SiC}$ by 31 hour treatment in $\mathrm{Ar}-3.5 \% \mathrm{Cl}_{2}$ at $1000^{\circ} \mathrm{C}$. Normal load, $5 \mathrm{~N}$, sliding velocity $14.7 \mathrm{~cm} / \mathrm{s}$.

Wear track profiles were obtained from the specimens at the end of each test and were used to calculate the volume of CDC removed by wear. Figures 20 and 21 show the wear track profiles after 260 and $1360 \mathrm{~m}$ sliding distance respectively. The volume of CDC removed was calculated in each case and is plotted as a function of sliding distance in Figure 22. After an initial run-in period in which the wear rate is slightly higher, the wear for distances above $500 \mathrm{~m}$ is approximately linear with distance at a value of $1.1 \times 10^{-6} \mathrm{~mm}^{3} / \mathrm{N} \mathrm{m}$. This is approximately two orders of magnitude lower than the wear rate of $1.24 \times 10^{-4} \mathrm{~mm}^{3} / \mathrm{N} \mathrm{m}$ for untreated $\mathrm{SiC}$ running in the same test rig under similar conditions. 


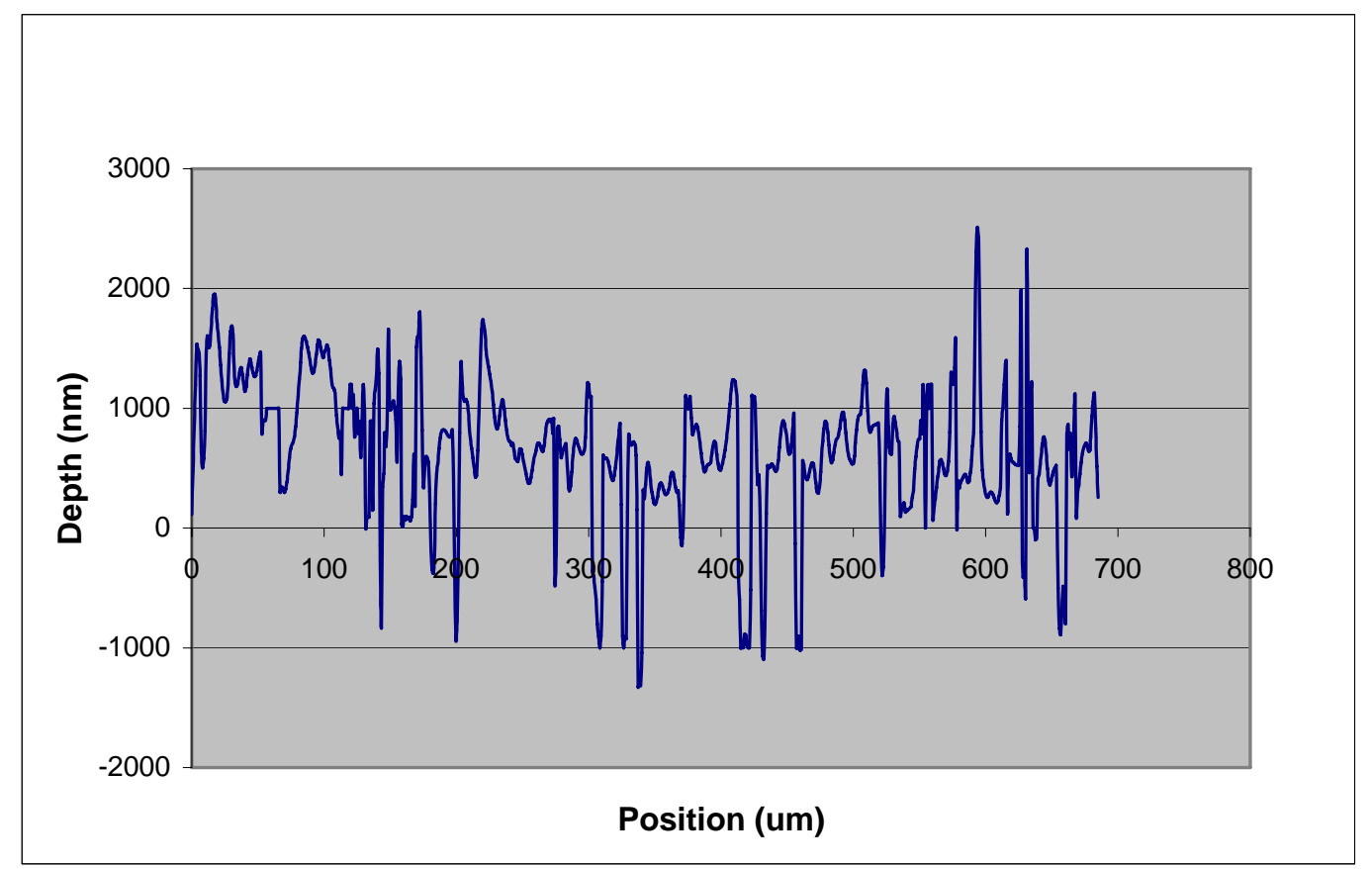

Figure 20. Wear track profile for CDC treated SiC specimen after $260 \mathrm{~m}$ sliding in pin-on-disk test.

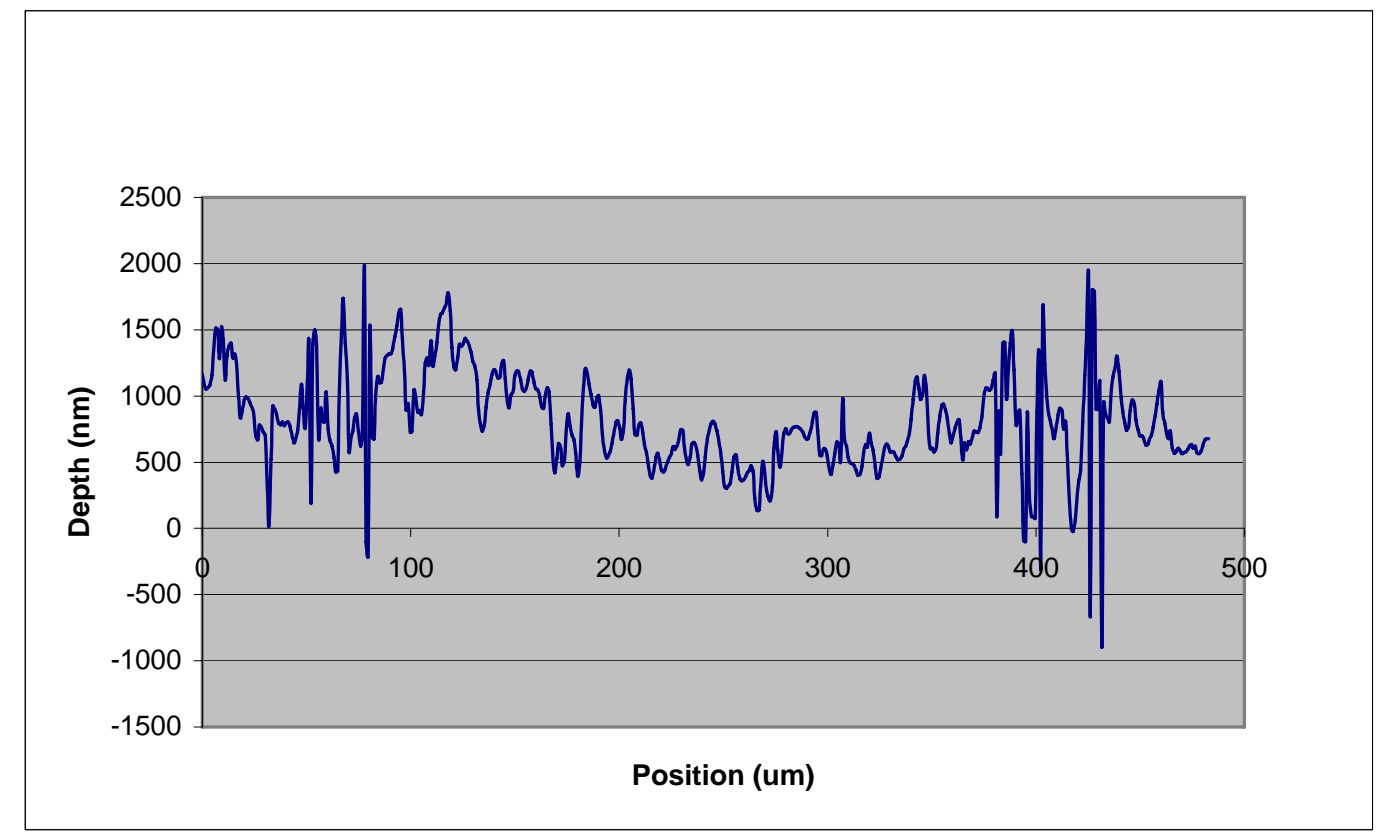

Figure 21. Wear track profile for CDC treated SiC specimen after $1360 \mathrm{~m}$ sliding in pin-on-disk test. 


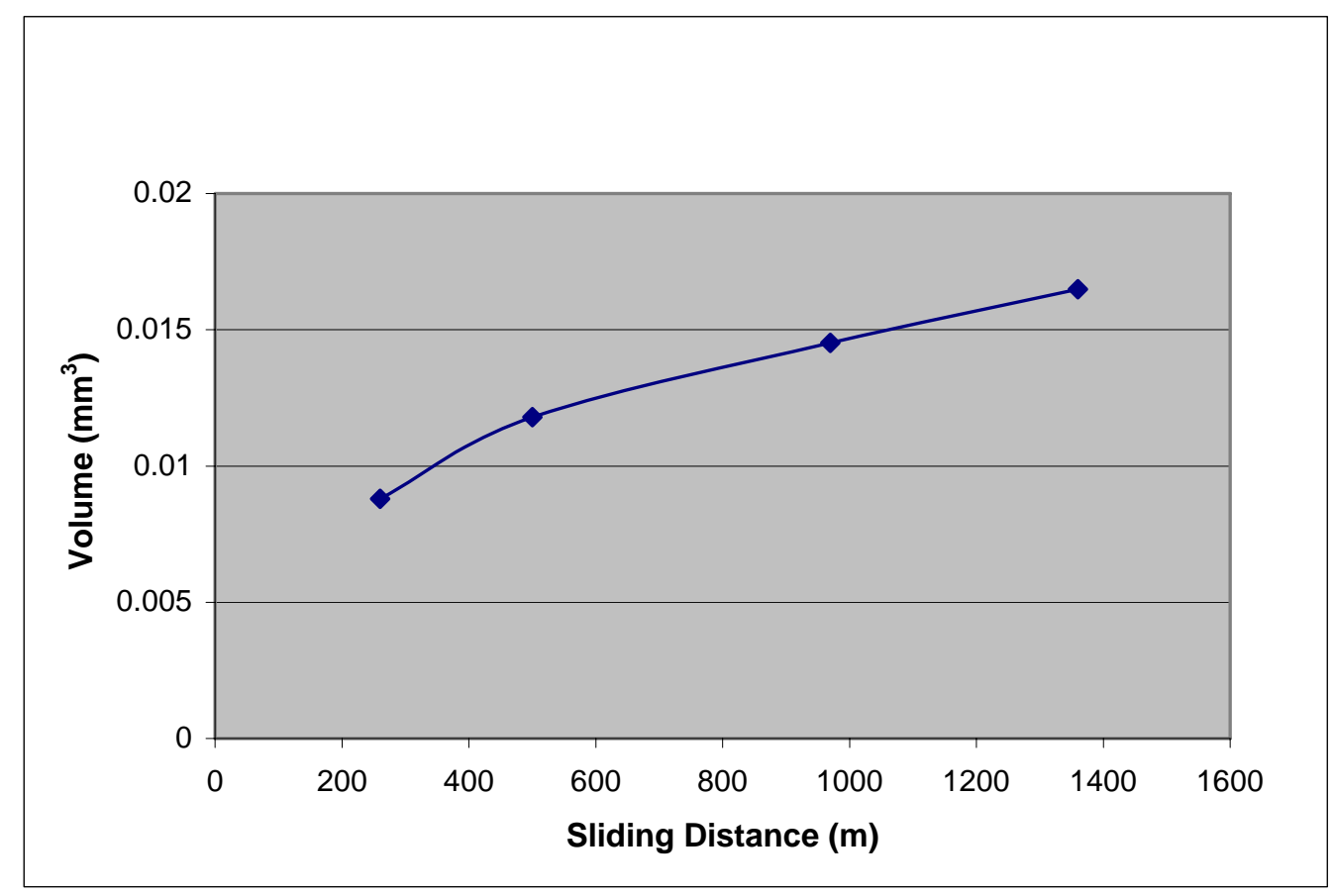

Figure 22. Wear volume versus sliding distance for CDC in pin-on-disk test with 3/8” silicon nitride ball as load of $5 \mathrm{~N}$ and sliding velocity of $14.7 \mathrm{~cm} / \mathrm{s}$.

Wear measurements were performed on several test coupons with different hardness and surface finish as a result of synthesis at different temperatures and with different hydrogen concentrations. The results consistently showed lower wear for samples treated at higher temperatures and lower wear for softer specimens. Overall, low wear rates were more closely predicted by samples with low friction coefficients than by samples with high hardness. The wear mechanism of CDC appears to be more complex than the simple mechanisms proposed for ceramic materials, which would predict that wear rates should be inversely proportional to the hardness of the ceramic. ${ }^{12}$ 


\section{Tribology of NFC/CDC Couples}

Near Frictionless Carbon (NFC) is another tribological carbon coating of interest in this study. NFC is produced by reactive ion assisted deposition of carbon to form a high hydrogen content film of diamond-like carbon (DLC). This DLC has the advantage that it can be deposited on any solid material, unlike CDC, which can grow only on carbide ceramics. CDC, however, is less costly to apply, and can grow to thicker layers than NFC. Because NFC has a higher hardness than CDC, it is not useful to deposit NFC on CDC, since the CDC can flex enough to crack and spall the NFC. However, NFC can be coated onto other hard substrates, which slide against CDC. The performance of a NFC/CDC tribological couple was investigated using the CSEM tribometer at Argonne National Laboratory and compared with the performance of a steel ball sliding against CDC.

The CDC layer was produced by treating alpha $\mathrm{SiC}$ in pure $\mathrm{Cl}_{2}$ gas for four hours at $1000^{\circ} \mathrm{C}$. The CDC layer was mechanically polished before testing to reduce the friction coefficient. The CDC was tested against a steel ball at $60 \mathrm{rpm}$ with a $5 \mathrm{~N}$ applied load. The results are shown in Figure 23.

Specimen \#75, Test 73-74

in Air (25\%RH) and in Nitrogen (0\%RH) , 60rpm, 5N load, 20 min sliding

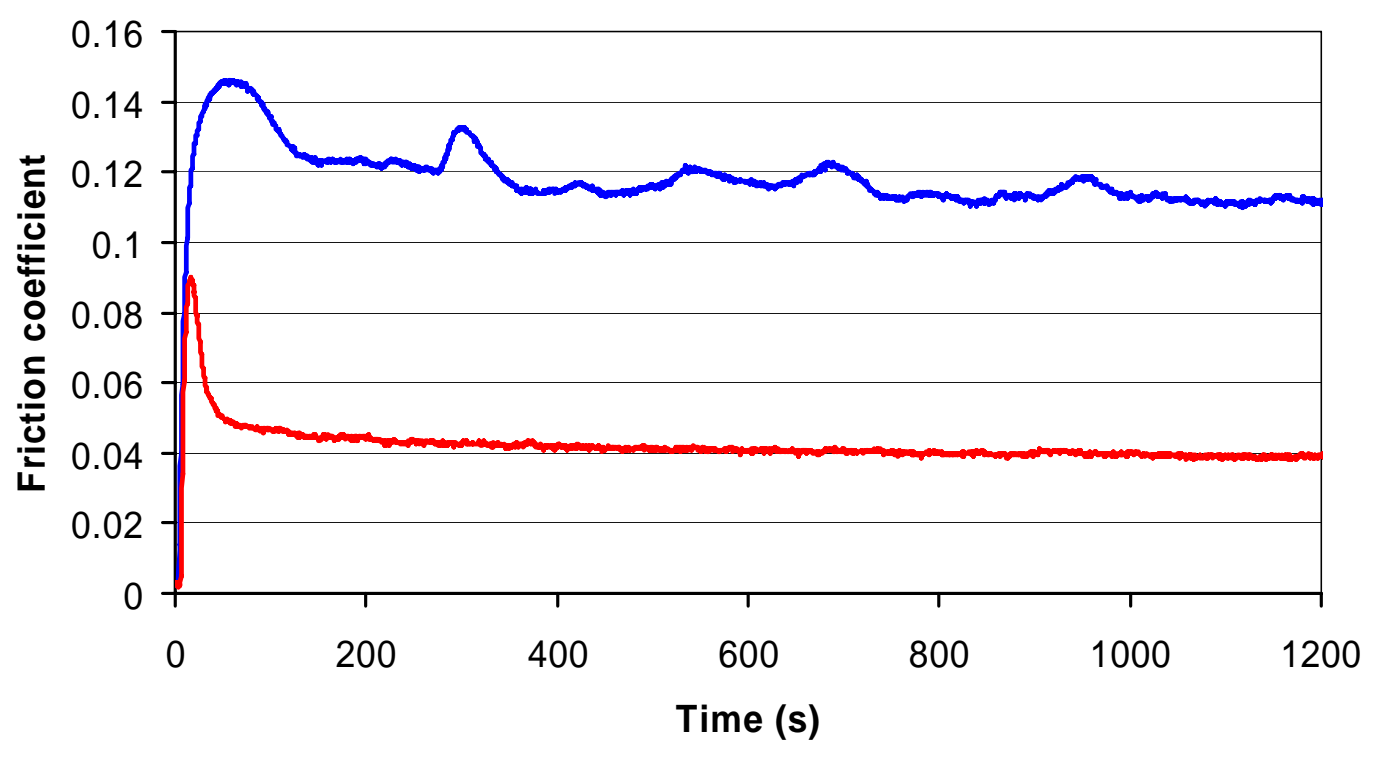

Figure 23. Friction coefficient versus sliding time for steel ball sliding against a polished CDC layer in laboratory air and in dry nitrogen. Polishing of the CDC surface lowers the friction coefficient to the range of 0.1 , and testing in dry nitrogen reduces it further to the range of 0.04 . 
The steel ball was then coated with a thin ( $<5$ micrometer) layer of NFC and the test was repeated. The results are shown in Figure 24. In both laboratory air and in dry nitrogen, the presence of the NFC coating on the steel ball further reduces the friction coefficient in comparison to sliding against steel.

\section{Specimen \#75(CDC), Ball NFC-6, Test 75-76} in Air (35\%RH) and in Nitrogen (0\%RH) , 60rpm, 5N load, 20 min sliding

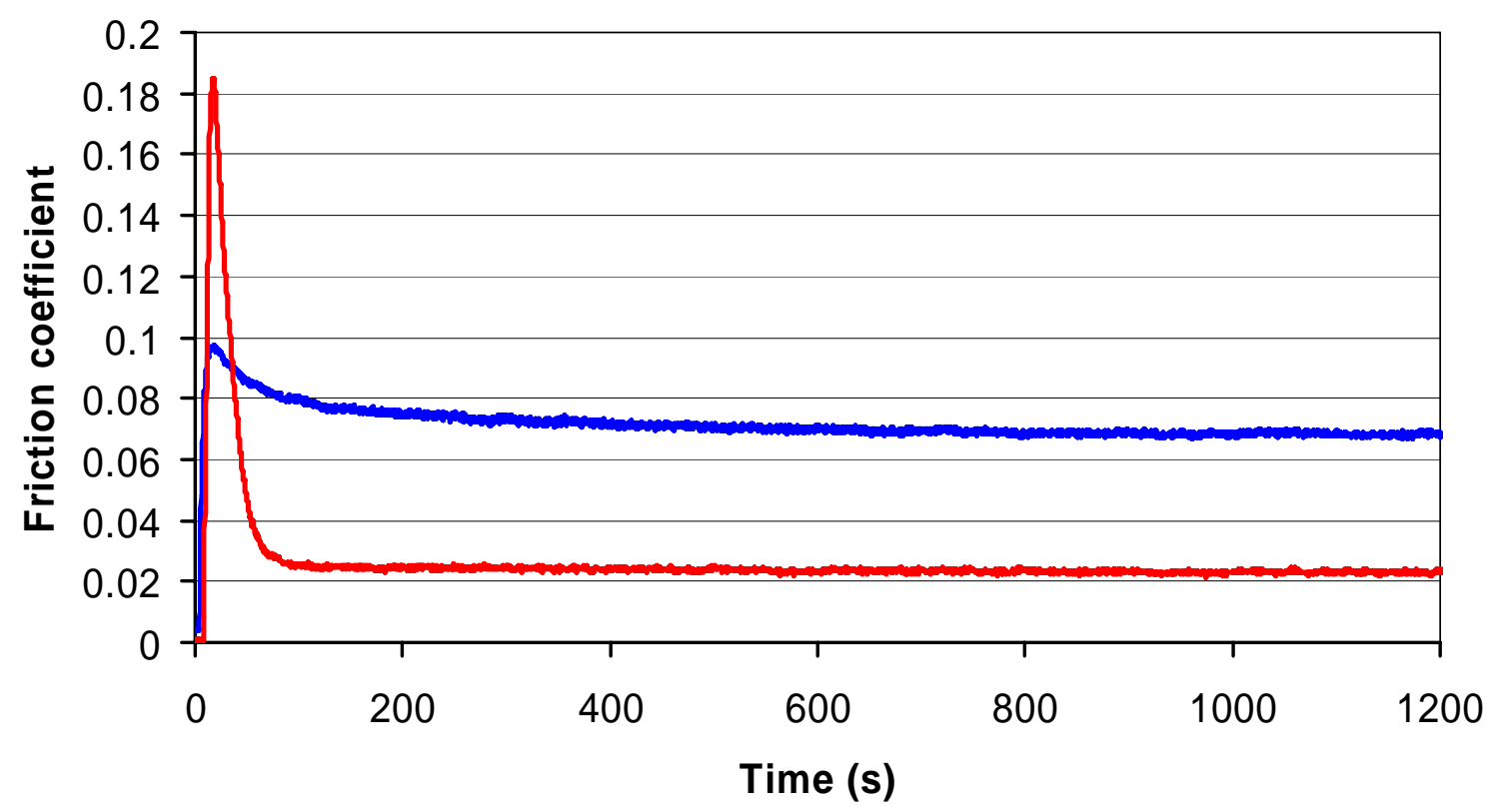

Figure 24. Friction coefficient versus sliding time for NFC coated steel ball sliding against a polished CDC layer in laboratory air and in dry nitrogen. With a NFC coating on the steel ball, s the friction coefficient in laboratory air drops to the range of 0.07 , and testing in dry nitrogen reduces it further to the range of 0.02 , nearly a $50 \%$ reduction from the value without NFC.

Although the NFC coating is much thinner than the CDC layer, it is resistant to wear during the test. Figure 25 is a three dimensional profilometry representation of the ball after testing. There is a smoothed region where the ball was in contact with the CDC during sliding, but no indication of significant wear or of penetration of the wear through the NFC to the underlying steel. 


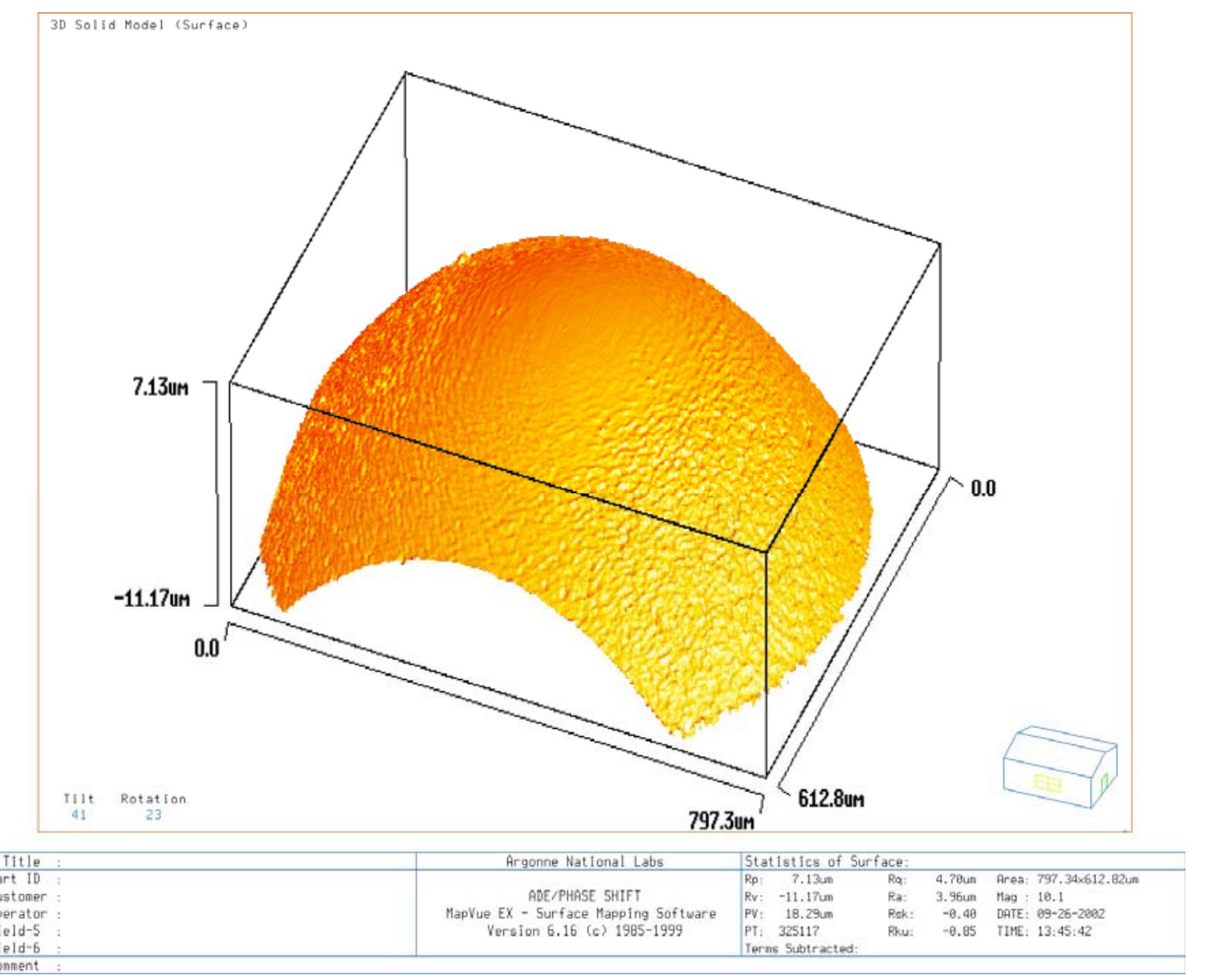

Figure 25. Three dimensional profilometry trace of NFC coated steel ball after testing against CDC, and before any cleaning. Note that there is no indication of a transfer layer or any significant sign of wear of material from the surface. 


\section{J. Performance of CDC in pump seal tests}

CDC performance in pump seal tests was investigated using the dynamic seal test facility at Argonne National Laboratory. A CDC coating was grown onto a 2" diameter pump seal ring which was installed in the ANL test machine to run against a hardened graphite ring. Figure 26 shows a photograph of the Argonne dynamic test facility.

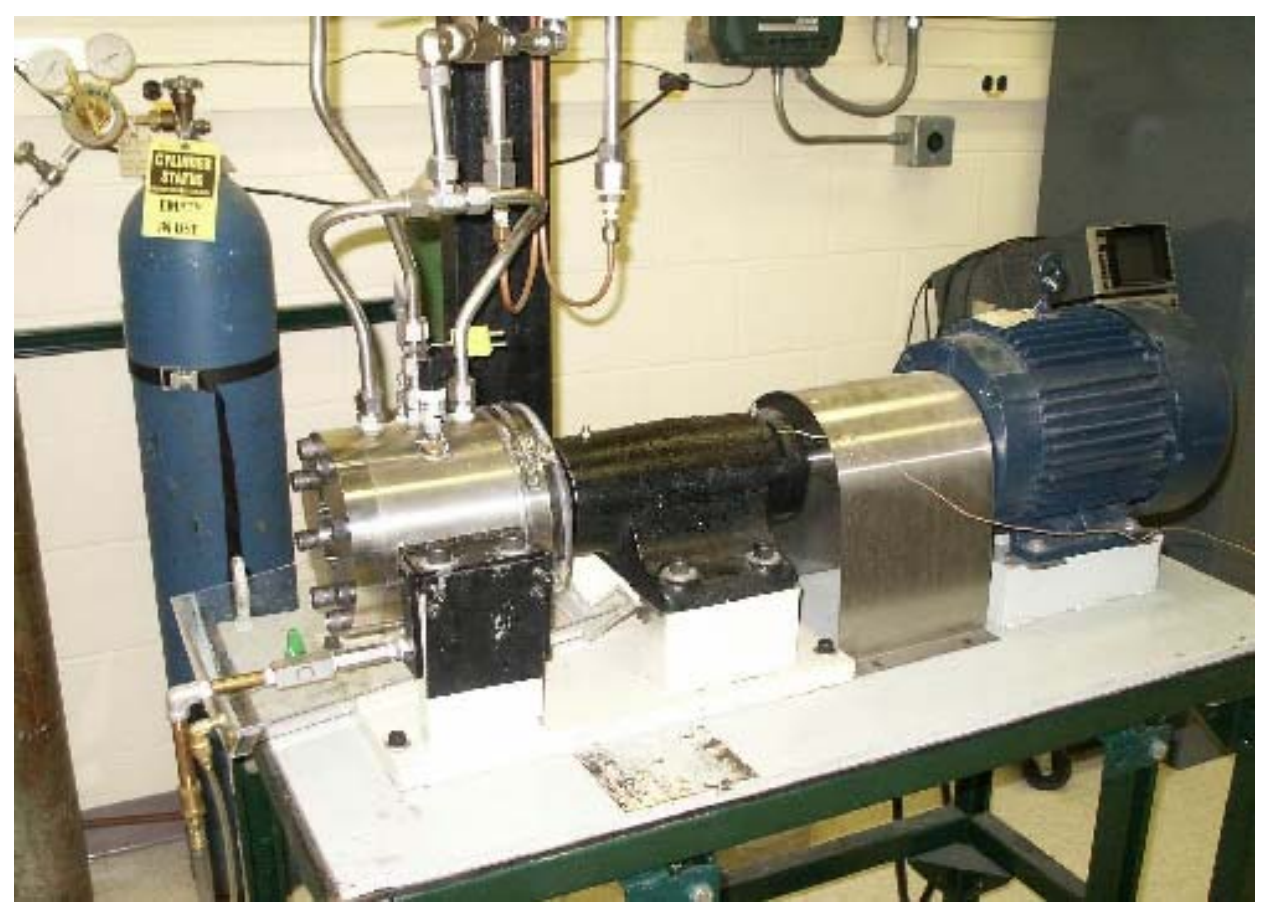

Figure 26. photograph of Dynamic Seal Test Facility at Argonne National Laboratory.

The seals are installed in a pump driven by an electric motor to pump deionized water under controlled pressure and flow conditions. Figure 27 shows the detail of the seal ring installation in the pump test facility. A series of tests were performed at a pump rotation speed of $3600 \mathrm{rpm}$. The test was initiated by running the pump in at a pressure of $20 \mathrm{psi}$ for one day. Subsequently, the pressure was increased in steps of 20 psi each day to a maximum pressure of $100 \mathrm{psi}$, and then the test was run for six days at 100 psi. The seals were removed and measured at the end of each day to evaluate the degree of wear. In addition, the seals were monitored for fluid leakage. A small amount of water leaked during the initial break-in test at 20 psi, but no further leakage was observed as the pressure increased. 


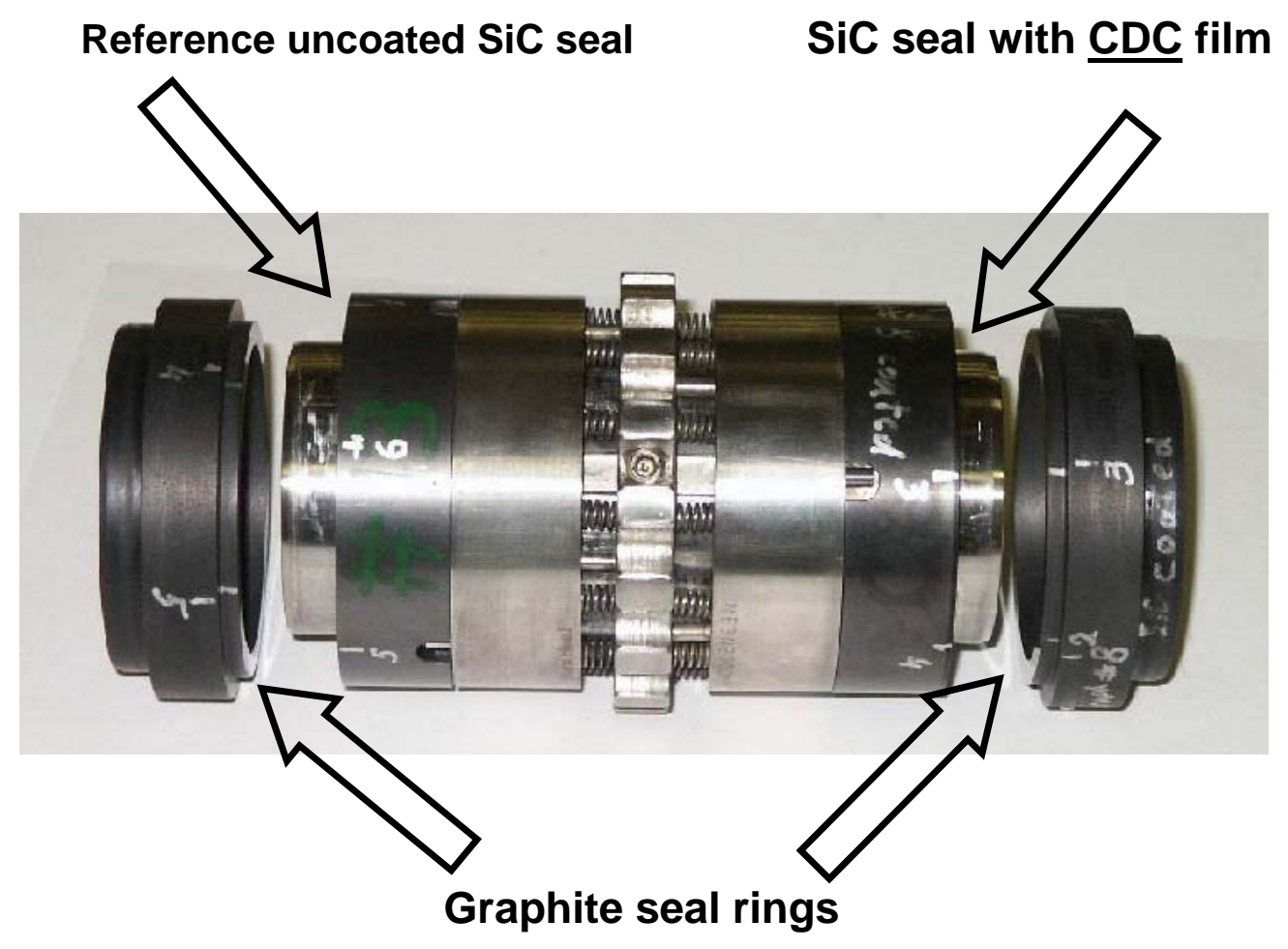

Figure 27. Detail of Seal Ring assembly in dynamic seal tester.

Figure 28 is an three dimensional non-contact profilometry scan of the surface of the CDC coated seal at the end of one day of testing at 20 psi. Wear lines are apparent in the contacting surface of the seal ring, and a groove about 5 micrometers deep has formed at the inner edge of the contact surface, but the depth of these wear features is small compared to the thickness of the CDC layer. Figures 29 through 33 show the surfaces at the end of each of the tests in the test from 40 psi through 6 days running at 100 psi. The overall wear is approximately 1 micrometer deep, and the groove near the inner edge of the contact surface has deepened to about 7 micrometers. These distances are still very small compared to the thickness of the CDC coating on these rings and indicate that CDC coated seals would have extended lifetimes in comparison to uncoated seals in pumping service under these conditions. 


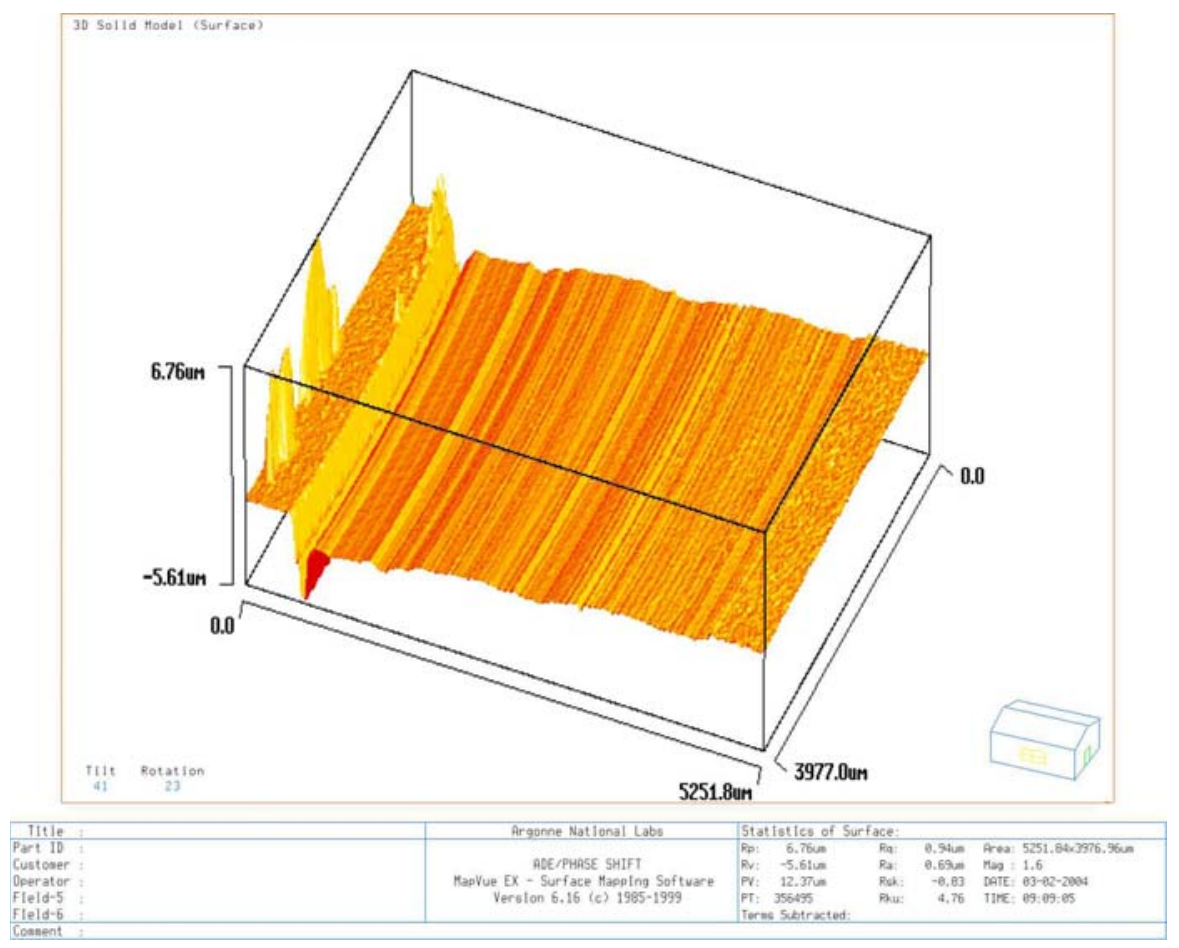

Figure 28. Non-contact profilometry scan of CDC treated SiC seal after one day testing in Dynamic Seal Test facility at 20 psi.

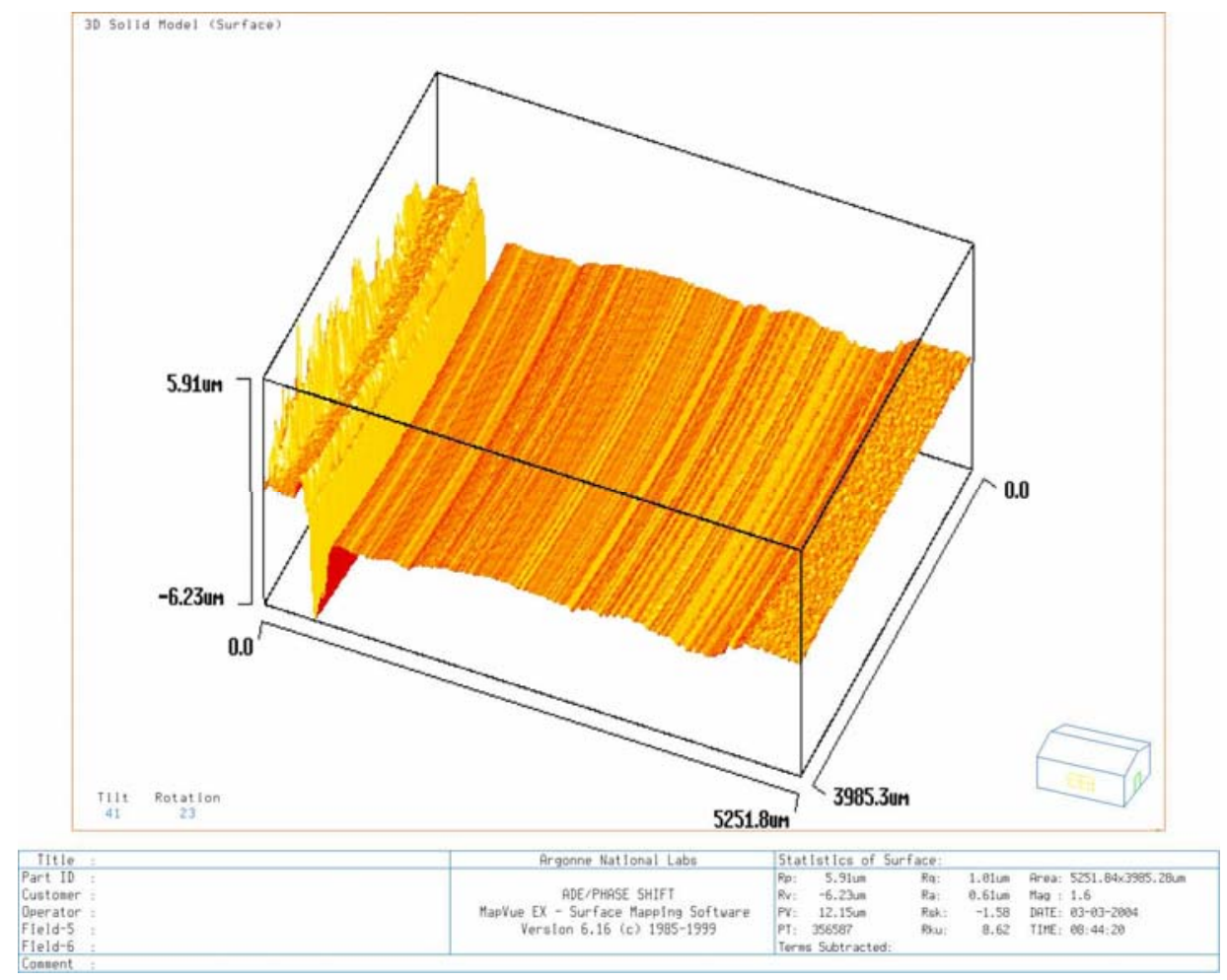

Figure 29. Non-contact profilometry scan of CDC treated SiC seal after one day testing in Dynamic Seal Test facility at 20 psi and one day testing at 40 psi.. 


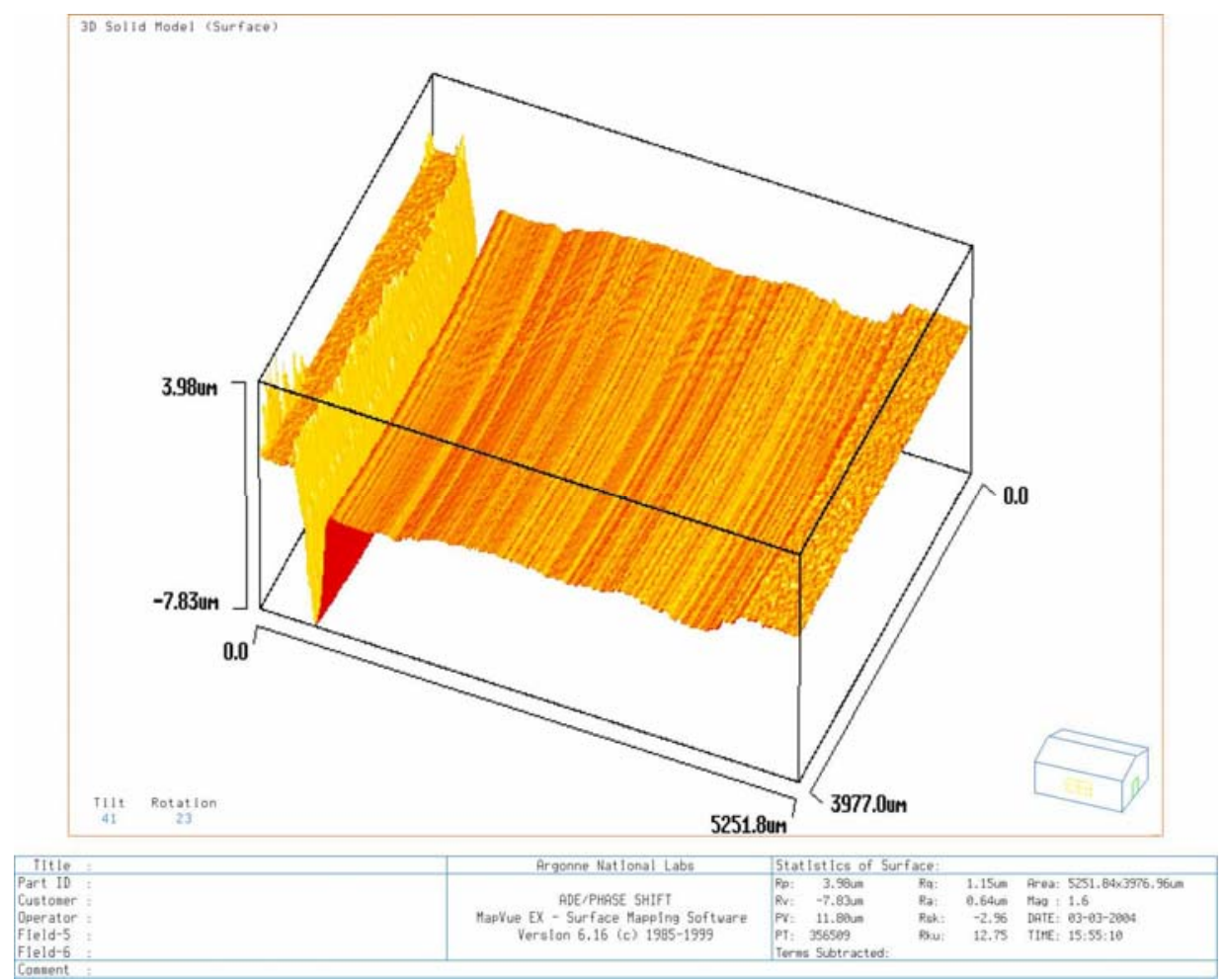

Figure 30. Non-contact profilometry scan of CDC treated SiC seal after one day testing in Dynamic Seal Test facility at $20 \mathrm{psi}$, one day testing at $40 \mathrm{psi}$ and one day testing at $60 \mathrm{psi}$.

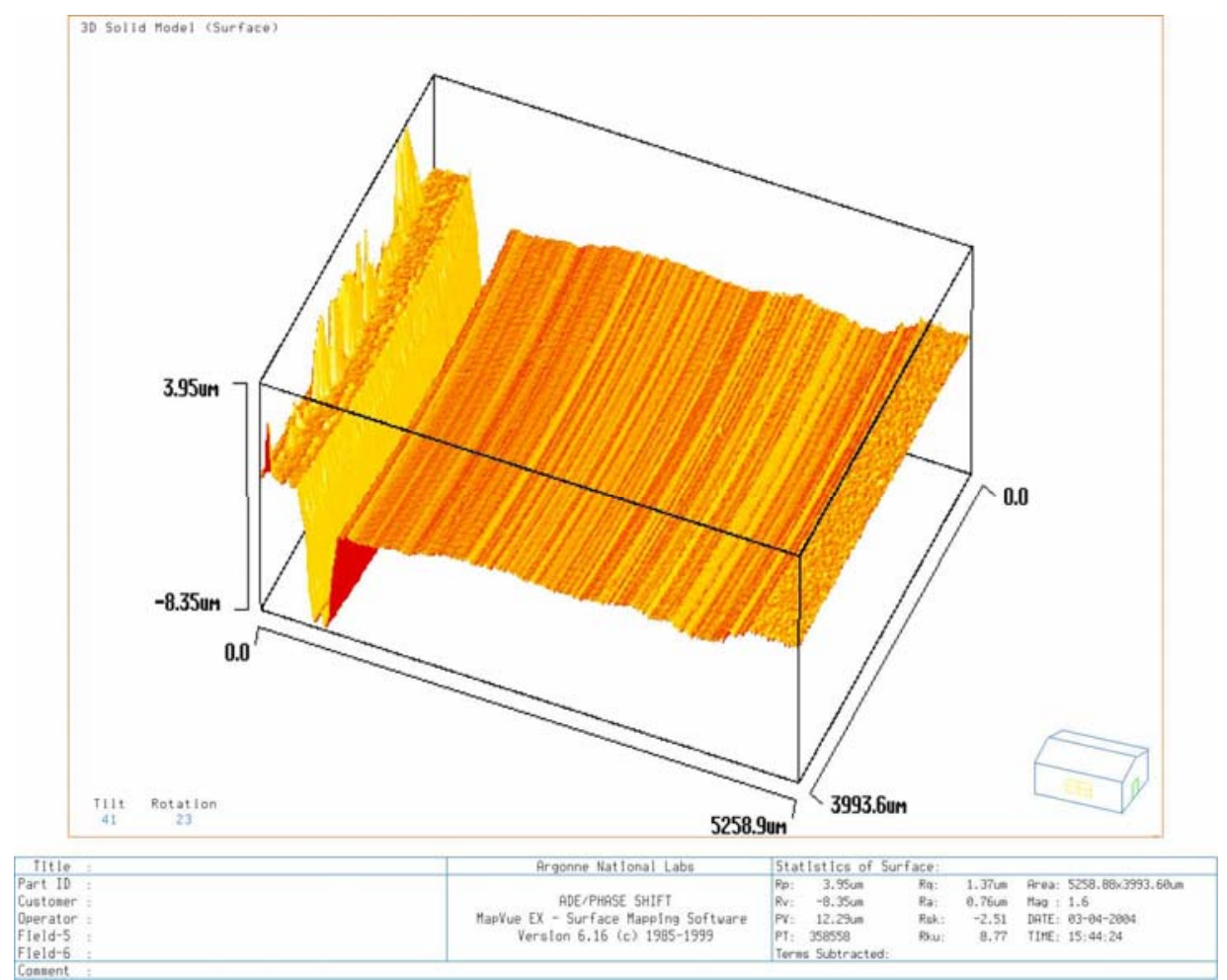

Figure 31. Non-contact profilometry scan of CDC treated SiC seal after one day testing in Dynamic Seal Test facility at 20 psi, one day testing at 40 psi, one day testing at 60 psi and one day testing at 80 psi.. 


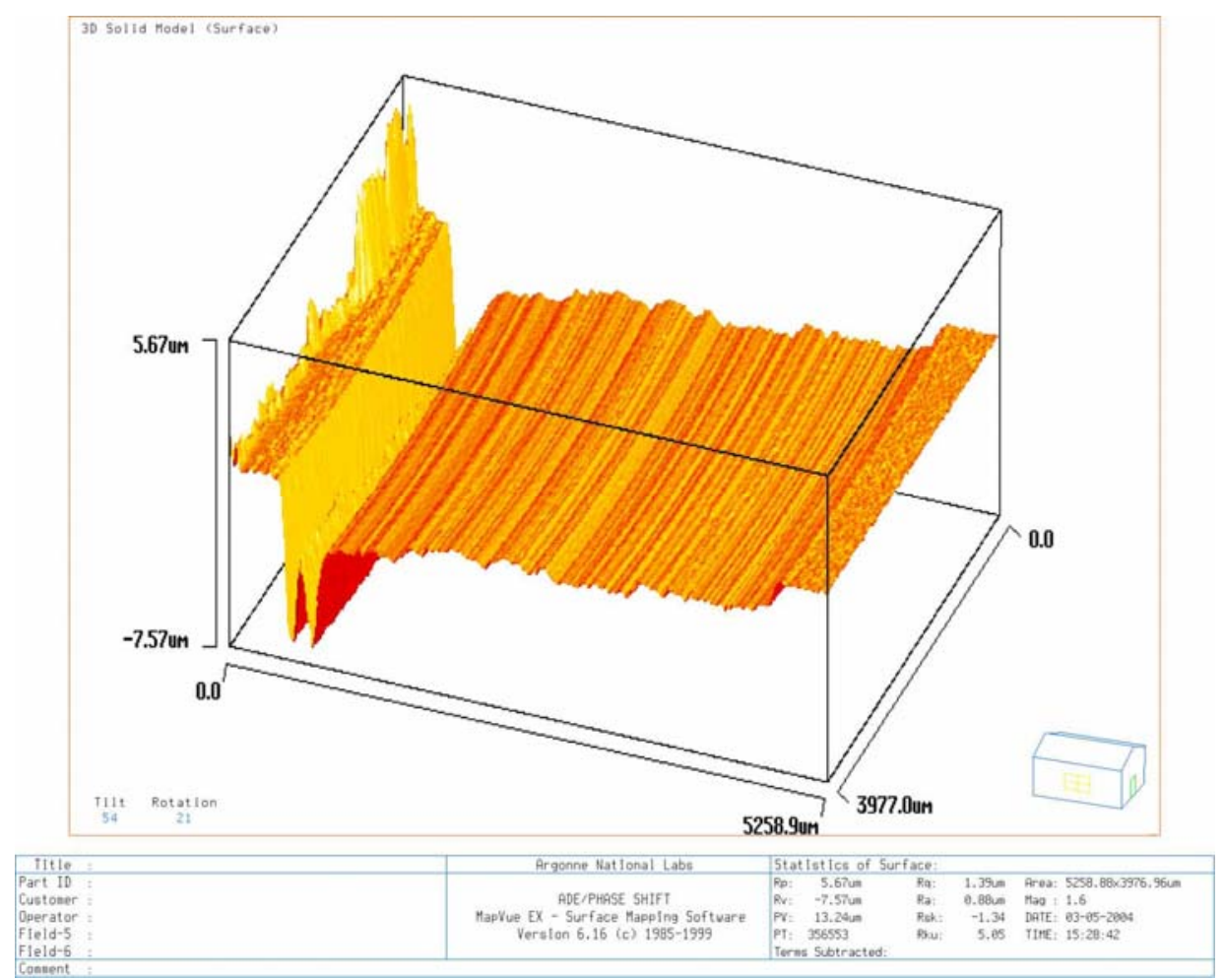

Figure 32. Non-contact profilometry scan of CDC treated SiC seal after one day testing in Dynamic Seal Test facility at $20 \mathrm{psi}$, one day testing at $40 \mathrm{psi}$, one day testing at $60 \mathrm{psi}$, one day testing at 80 psi and one day testing at 100 psi.

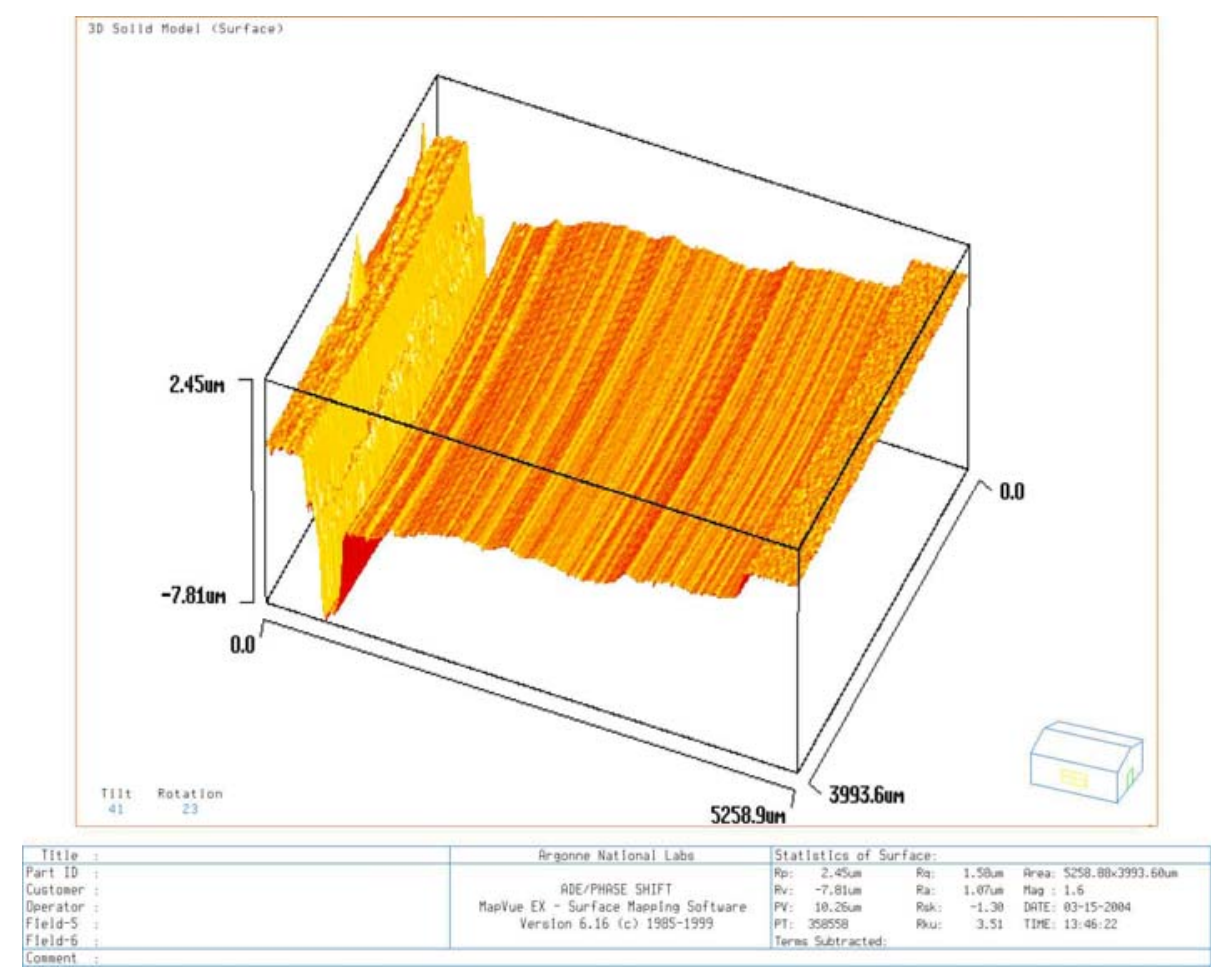

Figure 33. Non-contact profilometry scan of CDC treated SiC seal after one day testing in Dynamic Seal Test facility at $20 \mathrm{psi}$, one day testing at $40 \mathrm{psi}$, one day testing at $60 \mathrm{psi}$, one day testing at $80 \mathrm{psi}$ and eight day testing at $100 \mathrm{psi}$. 


\section{Accomplishments}

The following major technical tasks toward improving performance of seals and bearings in high speed rotating equipment have been accomplished.

- Low cost, reduced friction carbon coatings of Carbide Derived Carbon (CDC) have been produced on commercial $\mathrm{SiC}$ materials by treatment in chlorine containing gases in the temperature range between $850^{\circ} \mathrm{C}$ and $1200^{\circ} \mathrm{C}$.

- The mechanical properties (hardness by nano-indentation) and tribological properties (friction coefficient versus silicon nitride in pin-on-disk tribometer) of CDC have been characterized.

- The effects of changes in process parameters (temperature, reactive gas composition as $\% \mathrm{Cl}_{2}$ in binary gas mixtures with an inert carrier gas, and $\mathrm{Cl}_{2} / \mathrm{H}_{2}$ or $\mathrm{Cl}_{2} / \mathrm{HCl}$ ratio in multi-component gas mixtures) on the properties of the CDC have been characterized. Methods to produce CDC with controlled hardness and friction coefficient have been identified.

- The tribological benefits of NFC coatings on the counterface during sliding in a pin-ondisk test have been identified.

- The role of water vapor in the testing environment on the friction coefficient of CDC has been characterized.

- The benefits of post-treatment in hydrogen after synthesis on the physical and tribological properties of CDC have been identified.

- A provisional patent application, "Hydrogen Treatment of Carbide Derived Carbon for Modification of Properties,” by M. McNallan, Y. Gogotsi, A. Erdemir, A. Lee, C. White, and R. Zhu, was filed to the U.S. Patent Office, May 5, 2005 for the process of treating CDC in hydrogen to improve its tribological properties.

- The improved performance and wear resistance of CDC treated pump seal rings in service has been verified by tests up to 100 hours at 100 psi in the dynamic seal tester at Argonne National Laboratory.

- Carbide Derivative Technologies, Incorporated (CDTI) is an Illinois corporation, which was organized to develop CDC as a commercial product for tribological applications. CDTI has produced a hot water pumping test rig consisting of a loop of four high power water pumps in which CDC treated and conventional seal systems can be tested in a simulation of a severe pump service application. CDTI has performed extensive characterization testing on CDC treated SiC pump seals in this system and demonstrated their improved performance over that of conventional $\mathrm{SiC}$ and alternative seal materials. CDTI has negotiated a license agreement for CDC technology from the University of Illinois, and is implementing a marketing strategy to bring CDC treated pump seals into the chemical and fluid processing industries. CDTI has also partnered with the University and Argonne National Laboratory in a follow-on proposal to the Department of Energy to commercialize this technology. 
5. Technical Presentations at National or International Meetings:

- NATO Advanced Research Workshop on Nanostructured Materials and Coatings for Biomedical and Sensor Applications, Kiev, Ukraine, August, 2002, Tribological Characterization of Carbide-Derived Carbon (CDC) Films in Dry and Humid Enviromnents, B. CARROLL, Y. GOGOTSI, A. KOVALCHENKO, A. ERDEMIR, M.J. MCNALLAN.

- 39th Annual Technical Meeting of the Society of Engineering Science, October 14-16, 2002 at Penn State University: Tribological Properties of Nanostructured Carbide-Derived Carbon (CDC) Films, by Y. Gogotsi, $\underline{B}$. Carroll, A. Kovalchenko, A. Erdemir, M.J. McNallan

- 2002 MRS Fall Meeting in Boston, MA, December 2, 2002: Characterization and Tribological Testing of Carbide-Derived Carbon Films on SiC Substrates, by Beth Carroll, Yury Gogotsi, Michael McNallan, Ali Erdemir, Andriy Kovalchenko

- International Conference on Metallurgical Coatings and Thin Films, San Diego, CA, May 1, 2003, Structure and Composition Optimization of CarbideDerived Carbon Films for Tribological Applications, A. Kovalchenko; Y. Gogotsi; A. Erdemir; M. McNallan; B. Carroll.

- Society of Tribologists and Lubrication Engineers 2003 Annual Meeting, New York City, May 1, 2003, Effect of Annealing and Environment on the Tribological Behavior of Carbide-Derived Carbon Films, Beth Carroll, Yury Gogotsi, Michael McNallan, Ali Erdemir, Andriy Kovalchenko.

- International Conference on Metallurgical Coatings and Thin Films, San Diego, CA, April 21, 2004, Effects of High-Temperature Hydrogenation Treatment on Sliding Friction and Wear Behavior of Carbide-Derived Carbon Films, by A. Erdemir, A. Kovalchenko, M.J. McNallan, A. Lee, Y. Gogotsi and B. Carroll.

- Society of Tribologists and Lubrication Engineers 2004 Annual Meeting, Toronto, Canada, May 3, 2004, Effects of Test Conditions and Hydrogen Treatment on Sliding Friction and Wear Behavior of Carbide-Derived Carbon Films, by M.J. McNallan, A. Lee, A. Erdemir, A. Kovalchenko, and Y. Gogotsi.

- ASM Materials Solutions Conference, Columbus, Ohio, October 18-21, 2004, Carbide Derived Carbon Surface Treatments for Seal Faces and Tribological Applications, by Allen Lee ${ }^{1}$, Michael McNallan, FASM ${ }^{1}$, Dr. Ali Erdemir, FASM ${ }^{2}$ Andriy Kovalchenko ${ }^{2}$ and Yury Gogotsi ${ }^{3}$.

- $107^{\text {th }}$ Annual Meeting and Exposition of the American Ceramic Society, April 12, 2005, Baltimore, MD, .Carbide Derived Carbon - Low Friction Conversion Coatings for Carbide Ceramics, by Michael McNallan, Allen Lee, Christopher White, Ranyi Zhu, Ali Erdemir, Andriy Kovalchenko, Yury Gogotsi

- $8^{\mathrm{TH}}$ APPLIED DIAMOND CONFERENCE/NANOCARBON 2005, MAY 15-19, 2005, Argonne, IL, Effects of Synthesis Parameters on Properties of Carbide Derived Carbon Formed on SiC, by A. Lee, C. White, R. Zhu, M. McNallan, A. Erdemir, Y. Gogotsi.

- $8^{\mathrm{TH}}$ APPLIED DIAMOND CONFERENCE/NANOCARBON 2005, MAY 1519, 2005, Argonne, IL, Reactive Ion Etching of Multiphase Structures for 
CDC Synthesis, by P. Gupta, M. Tlustochowicz, R. Zhu, C. White, M. McNallan, A. Erdemir, B. Prorok, Y. Gogotsi (poster)

- ASM International Surface Engineering Congress, Minneapolis, MN, August 3, 2005, Tribology of Carbide Derived Carbon Coatings Grown on Tungsten Carbide, by M. Tlustochowicz, M. McNallan, A. Erdemir, R. Radhakrishnan, and S. Sudarshan, 


\section{Publications}

- "Tribological Characterization of Carbide-Derived Carbon (CDC) Films in Dry and Humid Environments,” B. CARROLL, Y. GOGOTSI, A. KOVALCHENKO, A. ERDEMIR, M.J. McNALLAN, Nanostructured Materials and Coatings for Biomedical and Sensor Applications, Y. Gogotsi, I. Uvarovna, Eds., Kluwer Scientific Publishers, Dordrecht, NL, 2003, 119-130.

- "Effects of Humidity on the Tribological Properties of Carbide Derived Carbon (CDC) Films on Silicon Carbide,” B. Carroll, Y. Gogotsi, A. Kovalchenko, A.Erdemir, M. McNallan, Tribology Letters, 15, 2003, pp 51-55

- "Effects of High-Temperature Hydrogenation Treatment on Sliding Friction and Wear Behavior of Carbide-Derived Carbon Films,” A. Erdemir, A. Kovalchenko, M.J. McNallan, S. Welz, A. Lee, Y. Gogotsi, B. Carroll, Surface and Coatings Technology, 188-189, 2004, pp 588-593.

- "Nano-structured Carbide Derived Carbon (CDC) Films and Their Tribology,” by Michael McNallan, Daniel Ersoy, Ranyi Zhu, Allen Lee, Christopher White, Sascha Welz, Yury Gogotsi, Ali Erdemir, and Andriy Kovalchenko, special issue on "Advances in Thin Films and Coatings," Journal of Tsinghua Science and Technology, 10, 2005, pp 699-703.

- "Kinetics of Conversion of Silicon Carbide to Carbide Derived Carbon," Allen Lee, Ranyi Zhu, M. McNallan, Journal of Physics: Condensed Matter, in press, 2006.

- "Synthesis and Tribology of Carbide-Derived Carbon Films,” A. Erdemir, A. Kovalchenko, C. White, R. Zhu, A. Lee, M.J. McNallan, B. Carroll, and Y. Gogotsi, International Journal of Applied Ceramic Technology, in press, 2006.

- "Hydrogen Treatment of Carbide Derived Carbon for Modification of Properties," by M. McNallan, Y. Gogotsi, A. Erdemir, A. Lee, C. White, and R. Zhu, Provisional Patent application filed to the U.S. Patent Office, May 5, 2005. 


\section{Conclusions}

CDC treatment of $\mathrm{SiC}$ seal and bearing surfaces can provide substantial benefits to the tribological performance of these systems by reducing the friction coefficients and wear rates in service. These include:

- $\quad$ Reduced friction and wear rates compared with untreated SiC or graphitic carbon materials.

- Low costs compared with diamond or diamond like carbon coatings

- The properties of the CDC can be modified by controlling the synthesis environment, particularly by growing the $\mathrm{CDC}$ in $\mathrm{Cl}_{2} / \mathrm{H}_{2}$ or $\mathrm{Cl}_{2} / \mathrm{HCl}$ gas mixtures.

- Treatment of the CDC in a hydrogen containing environment after synthesis further improves the properties, by removing residual chlorine in the structure and reducing the friction coefficient of the CDC by providing hydrogen termination of the surface carbon bonds. This is a similar mechanism to that which provides low friction coefficients in near frictionless carbon (NFC).

- Further reductions in friction and wear rates are obtained when NFC coated surfaces are run against CDC.

- $\quad$ CDC treatments can conveniently be performed on SiC pump seal rings and the performance of CDC coatings has been verified in an operating pump system pumping water at pressures up to 100 psi. 


\section{Recommendations}

CDC coatings on SiC pump rings have been shown to substantially improve performance both in terms of reduced friction losses and improved wear life. It is recommended that this system be moved toward commercialization with the development of CDC treatment furnaces that can process commercially significant numbers of pump seal rings at high rates and with low process costs. These coated rings can be supplied to potential customers for field-testing to verify these benefits in service. Additional validation work should also address process reliability and reproducibility of coating thickness and tribological properties so that service lives and friction reductions can be predicted with better precision. It may also be necessary to verify the compatibility of CDC with some of the process fluids used in chemical and energy conversion industries before these coatings will be widely accepted for use in these industries.

This work should be performed in collaboration with an industrial partner that can contribute to making these coatings commercially available to U.S. industries. A collaborative research proposal to address these tasks has been submitted by the University of Illinois at Chicago, together with Carbide Derivative Technologies, Inc (CDTI)., Argonne National Laboratory, and Drexel University to the U.S. Department of Energy to address these tasks. In addition, CDTI has signed an agreement to license the technology from the University of Illinois and is proceeding with the implementation of a marketing plan to make these parts available to the chemical and fluid handling industries. 


\section{REFERENCES}

1. S. Hogmark, P. Hollman, A. Alahelisten, P. Hendenqvist., "Direct current bias applied to hot flame diamond deposition produces smooth low friction coatings," Wear 200, pp 225-232, (1996).

2. R. Divakar, in S. Jahanmir (Ed.), Friction and Wear of Ceramics, Marcel Dekker, New York, pp. 357, 1994.

3. P. Hollman, H. Bjorkman, A. Alahelisten, S. Hogmark, "Diamond coatings applied to mechanical face seals," Surface and Coatings Technology 105, pp. 169-174 (1998).

4. R. F. Davis (Ed.), Diamond Films and Coatings, Noyes Publications, New Jersey, 1993.

5. P. J. Kelly, R. D. Arnell, M. D. Hudson, A. E. J. Wilson, G. Jones, "Enhanced mechanical seal performance through CVD diamond films," Vacuum 61, pp.61-74 (2001).

6. Q. Wei, J. Narayan, "Superhard Diamondlike Carbon: Preparation, Theory and Properties," International Materials Reviews, 45, pp 133-164 (2000)

7. Y. Gachon, C. Heau, "Study of Mechanical Behavior of Diamond-Like Carbon Coatings by Several Instrumented Tribometers," Thin Solid Films, 377-378, pp 360-365 (2000)

8. N. Ali, W. Ahmed, Q.H. Fan, C.A. Rego, "Optimizing Diamond Nucleation via Combined Pre-Treatments," Thin Solid Films, 377-378, pp 208-213, (2000)

9. Z.M. Zhang, X.C. He, H.S. Shen, F.H. Sun, M. Chen. Y.Z. Wan, "Pre-treatment for Diamond Coatings on free-shape WC-Co Tools, Diamond and Related Materials, 9, pp 1749-1752, (2000)

10. S. Amirhaghi, H.S. Rechal, R.J.K. Wood, D.W. Wheeler, "Diamond Coatings on Tungsten Carbide and Their Erosive Wear Properties," Surface and Coatings Technology, 135, pp 126138 (2001)

11. E. Johansson, B.Hjorvarsson,. T. Ekstrom, M. Jacob,. "Hydrogen in Carbon Nanostructures," Journal of Alloys and Compounds, 330-332, pp 670-675, (2002)

12. Reference on wear mechanism and prediction of wear rates.

13. Gogotsi, Y. G. \& Yoshimura, M. Formation of carbon films on carbides under hydrothermal conditions. Nature 367, 628-630 (1994).

14. Gogotsi, Y. G., Kofstad, P., Nickel, K. G. \& Yoshimura, M. Formation of sp3-bonded carbon upon hydrothermal treatment of SiC. Diamond and Relat. Mater. 5, 151-162 (1996).

15. Gogotsi, Y. G., Jeon, J. D. \& McNallan, M. J. Carbon coatings on silicon carbide by reaction with chlorine-containing gases. J. Mater. Chem. 7, 1841-1848 (1997).

16. Zheng, J., Ekstrom, T. C., Gordeev, S. K. \& Jacob, M. Carbon with an onion-like structure obtained by chlorinating titanium carbide. J. Mater. Chem. 10, 1039-1041 (2000).

17. Ersoy, D. A., McNallan, M. J., Gogotsi, Y. \& Erdemir, A. Tribological properties of carbon coatings produced by high temperature chlorination of silicon carbide. STLE Tribology Transactions 43, 809-815 (2000).

18. Y. Gogotsi, S. Welz, D. Ersoy, M. McNallan, "Conversion of Silicon Carbide to Crystalline Diamond Structured Carbon at Ambient Pressure,” Nature, 411, pp 283-287, (2001) 